\title{
Single and Multi-Stage Manufacturing Systems Under Imperfect Quality Items with Random Defective Rate, Rework and Scrap
}

\author{
Hadi Mokhtari ${ }^{*}$, Aliakbar Hasani², Saeed Dehnavi-Arani ${ }^{3}$ \\ ${ }^{1}$ Associate Professor, Department of Industrial Engineering, Faculty of Engineering, \\ University of Kashan, Kashan, Iran \\ ${ }^{2}$ Associate Professor, Department of Industrial Engineering and Management, \\ Shahrood University of Technology, Shahrood, Iran \\ ${ }^{3}$ Department of Industrial Engineering, Faculty of Engineering, \\ University of Yazd, Yazd, Iran
}

\section{Hadi Mokhtari}

- Postal code: 8731753153

- Tel.:+983155912445

- Mobile: +989124359296

- Email:mokhtari_ie@kashanu.ac.ir

\section{Aliakbar Hasani}

- Postal code: 3619995161

- Tel.: +989130937168

- Mobile: +989130937168

- Email:aa.hasani@shahroodut.ac.ir

\section{Saeed Dehnavi-Arani}

- Postal code: 8714881734

- Tel.:+983155801890

- Mobile: +989132603560

- Email: saeed.dehnavi86@gmail.com

\begin{abstract}
The classical manufacturing systems assume that all of produced items are of perfect quality. They also do not consider the rework process in manufacturing operations. Moreover, most of the previous literature consider single stage production-inventory systems and do not consider multi stage options. However, in real world production-inventory systems, production of defective items is inevitable, and a fraction of the produced items may be
\end{abstract}


defective. In addition, to avoid extra costs and consider environmental issues, organizations tend to reworking activities. We propose single and multi-stage production-inventory systems in manufacturing operations where the process is defective, rework is possible and a percent of items are scrapped. A main assumption, in the current paper, is that the defective rate is assumed to be uncertain parameter. The grey systems theory, as a mathematical tool to address the uncertain information in real-world situations, is utilized to model the random defective rate via a grey nonlinear programming problem. The proposed issues are investigated via numerical examples to assess the impact of grey parameters on optimal solutions.

Keywords: Grey Systems; Manufacturing Systems; Uncertain Systems; Multi Stage Manufacturing; Rework

Table 1 shows indices, parameters and variables used throughout the paper.

\section{Table $1<<$}

\section{Introduction}

One of the primary assumptions of the classical production-inventory problems is that all items are of perfect quality every time. However, in realworld situations, the production processes are not necessarily of perfect quality, and production of defective items is inevitable. Usually, a certain fraction of the items is defective which is due to poor quality of the production process or raw materials. In a multi-stage production system, products are transferred from one stage to the next stage, and every stage may produce a fraction of defective products. A production stage is affected by a number of inevitable undesirable factors, which make it rarely possible for a production machine/production system to produce perfect quality items every time. In fact, in some defective production systems, rework is usually used for imperfect items at every stage. The perfect items go to the next stage and finally become finished product at the final stage, and then go under consumption. Moreover, a fraction of imperfect items is of unacceptable quality and should be disposed as scrap at each stage. The 
decision of on the quality of a produced item is made by a quality control process in manufacturing companies.

In real world, there are many uncertain parameters affecting the decision-making process, outstandingly. Grey systems theory is a mathematical tool to address the uncertain information in real-world situations. The aim, in grey systems theory, is to enable the prediction and decision making in uncertain environments. In a real system, when the information is fully known, the system is entitled white system, and when the information is unknown, it is entitled black system. Moreover, when the system encounters with information with partially known information, it is entitled grey system. One of the common approaches in addressing uncertain decision making is stochastic programming, where analysis of scenarios is carried out to study an optimization problem under uncertainty. In such an approach, the uncertainty of parameters is addressed by a number of subproblems, each one is associated with scenario on the possible values of uncertain parameters. By analyzing the subproblems and studying their solutions, one hopes to discover the solution to the original problem by using probabilistic means like expected value. However, solving the subproblem may have some difficulties and great computational efforts are needed to solve subproblems. The grey programming (grey optimization) is one of potential approaches for avoiding the above problems in stochastic programming [1]. The major advantages of the grey programming (GP) against existing approaches are (i) GP will generate feasible ranges of decision variables and objective functions using the interpretation of the grey solutions and grey input parameters, (ii) GP will have lower computational efforts compared with the existing methods, and then is applicable to practical problems, and (iii) GP will not require distribution information (like probability based approaches) or membership function (like fuzzy based approaches) for input parameters, since interval numbers are acceptable for the input parameters [1]. 
In this paper, as our contribution, we propose a production-inventory problem where a manufacturer produces products via a finite production rate. It is assumed that the production process is defective and produces a percentage of imperfect items. The imperfect products are also under rework process to become perfect and return to consumption cycle. The aim is to determine optimal/economic production quantities in such a way that the total cost of the system is minimized. The traditional literature mostly considers single-stage production system, and the multi-stage production processes are rarely considered. Moreover, many of them addressed the constant defective rate in the manufacturing process, which is not a real condition. In addition, rare studies considered rework of defective items, and others do not consider this complementary process.

The rest of this paper is structured as follows. Section 2introduces the grey systems theory. Then, Section 3apply the grey systems theory principles to single and multi-stages manufacturing systems. Sections 4 considers two numerical examples and studies impact of grey parameters on optimal solutions. Finally, Section 5 concludes the paper.

\section{Literature Review}

The manufacturing process with rework has been studied and discussed extensively in literature (i.e., see [2] and [3]). Moreover, the impact of the rework process on imperfect products was evaluated as well. As one of the first papers, Salameh and Jaber [4] considered the raw material in the economic order lot size problem where there is an inspection process within a main production process. They assumed that the defective items were sold as a single batch at a discounted price. Also, they considered a probability density function for percentage of defective items. Besides, an inventory problem for multi-stage production process with imperfect items was presented by Ben-Daya and Rahim [5]. In their paper, a fixed percentage of 
defective items has been considered. In another work proposed by Ben-Daya et al., [6], they considered different inspection policies for the inventory inspection models in a single-stage environment. Moreover, a beta distribution has been assumed for the fraction nonconforming items. Ojha et al., [7] studied a reworkable item lot size quantity model under an imperfect production system. They considered single-stage production with producing the defective items at a constant rate. In addition, Sarker et al., [8] studied a multi-stage production environment where there is an imperfect manufacturing system. In that paper, they assumed that proportion of defective items is constant in each cycle. In other research presented by Biswas and Sarker [9], an optimal lot size quantity was calculated in a lean production system when there are reworks and scraps in the system. A singlestage production process with constant proportion of defective items was considered in that paper. Moreover, Wee and Widyadana [10] proposed, for raw material and deteriorating finished items, an economic production quantity model under rework condition. Their assumption also was singlestage system with constant rate of rework and deteriorating. Krishnamoorthi and Panayappan [11] evaluated the possible sales return for items with poor quality in a production process with rework allowed. They considered a constant proportion of defective in a single-stage manufacturing system. In another study, the various inspection options were investigated by Yoo, et al., [12], where they tried to manage the inventory with imperfect production. In this paper, a multi-stage system with constant defective rate for items was considered. Colledani and Tolio [13] proposed an analytical approach to jointly assess the effect of quality and performance in a multi-stage manufacturing system with fixed fraction of nonconforming items. Wee et al., [14] determined the production lot size for imperfect quality items when shortages are allowed for a single-stage system. In their paper, the percentage of imperfect items had a known probability density function. Additionally, Paul et al., [15] suggested a disruption system in a multi-stage 
manufacturing system. Moreover, Mahata [16] considered partial backlogging and fuzziness to calculate the production lot size under imperfect production system. In other words, some costs such as setup cost, average holding cost, backorder cost, raw material cost, labor cost as well as percentage of defective items were characterized as fuzzy numbers. Jaggi et al., [17] proposed and discussed an imperfect inventory model with twowarehouse with permissible delay in payments. The percentage of defective items in their paper was a random variable with a probability function. Kamali et al., [18] presented a multi-objective optimization inventory model for the single-buyer, multi-vendor problem with discounts. The authors considered each vendor had a fixed rate of items deterioration in a supply chain. Nobil et al., [19] considered the scrapped and rework items under economic production quantity incorporating shortages and allocations in a multi-stage manufacturing system. The percentage of defective has been known as constant parameter in this paper. Cheng et al., [20] proposed multiple disposals of defective inventories for an integrated imperfect production system. They assumed that there was a random fraction of defective item with a known probability density function. Mokhtari [21] proposed a joint production and order lot size problem considering the rework and defective manufacturing. The author considered the uncertainty for percentage of items by a probability function. Nobil, et al., [22] suggested an imperfect, shortage, rework, and scrapped single machine system with inspection, deficiency levels, and setup times. One of their assumption was that the expected proportion of produced defective items was known and constant. Mokhtari and Asadkhani [23] discussed an economic order quantity (EOQ) model with imperfect quality inventory including a probability density function with the inspection under batch replacement and returned items conditions. In another study, Mokhtari [24] proposed an optimal manufacturing system under both imperfect raw materials and products. In this paper, the defective rate of items has been assumed a 
constant number. Yang, et al., [25] incorporated the trade credit into an inventory problem with shortage and the constant defective items. Beranek and Buscher [26] suggested an integration between pricing and quality decisions under market segmentation by considering imperfect quality items. The proportion of imperfect quality items was constant and quality dependent. Adak and Mahapatra [27] proposed a three-layer supply chain system with imperfect items and variable production cost under deterioration. In this paper, it was assumed that the defection rate of finished item is fixed. A comparison between papers of literature review has been given in Table 2.

\section{$>>$ Table $2<<$}

\section{Theory of Grey Systems}

the current section, the concept of grey systems will be defined to be used in the sequel. A grey number $G(\otimes)$ is a number whose exact value is unknown, but a bounded interval within which the value lies is known (Lin et al., 2004). A grey system is a system that includes information as grey numbers; and a grey decision is a decision-making system for a grey system. A grey number $G(\otimes)$ is defined as an interval with known lower limit $\underline{G}$ and known upper limit $\bar{G}$ as $G(\otimes)=[\underline{G}, \bar{G}]$. One of the main advantages of grey system theory is that it works even if the probability distribution and membership functions cannot be recognized [28]. A grey number $G(\otimes)$ become a deterministic number or white number when its upper and lower limits are equal $\bar{G}=\underline{G}$. Some useful information on this approach is summarized in the sequel.

Definition 1. A grey number $G(\otimes)$ is defined as an interval with known lower and upper limits $G(\otimes)=[\underline{G}, \bar{G}]$ and unknown distribution information. 
Definition 2. The whitened value of a grey number $G(\otimes)$ which is shown by $\tilde{G}(\otimes)$ is defined as a deterministic number with a value lying between upper and lower limits.

$$
\underline{G} \leq \tilde{G}(\otimes) \leq \bar{G}
$$

The whitened value of grey number can be formulated by defining a new variable $\gamma \in[0,1]$ as follows.

$$
\tilde{G}(\otimes)=\gamma \bar{G}+(1-\gamma) \underline{G}
$$

The whitened value $\tilde{G}(\otimes)$ equals to upper limit $\bar{G}$ if $\gamma=1$, and equals to lower limit $\underline{G}$, if $\gamma=0$. Moreover, if $\gamma$ gets a value between 0 and 1 , the whitened value $\tilde{G}(\otimes)$ gets an intermediate value between upper and lower limits. The grey linear programming (GLP) is a method for decision making under uncertainty. It is a development of the traditional linear programming method. The GLP can be presented as following standard form:

$$
\operatorname{Max} f=c(\otimes) x
$$

Subject to $A(\otimes) x \leq b$

$$
x \geq 0
$$

in which

$$
\begin{gathered}
c(\otimes)=\left[c_{1}(\otimes), c_{2}(\otimes), \ldots, c_{m}(\otimes)\right] \\
x^{\mathrm{T}}=\left(x_{1}, x_{2}, \ldots, x_{m}\right) \\
b^{\mathrm{T}}=\left(b_{1}, b_{2}, \ldots, b_{n}\right) \\
A(\otimes)=\left[a_{i j}(\otimes)\right] \quad \forall i=1,2, \ldots, n, \quad j=1,2, \ldots, m
\end{gathered}
$$

and

$$
c_{j}(\otimes)=\left[\underline{c}_{i j}, \bar{c}_{i j}\right] \text { and } a_{i j}(\otimes)=\left[\underline{a}_{i j}, \bar{a}_{i j}\right] \quad \forall i=1,2, \ldots, n, j=1,2, \ldots, m
$$

The optimal solution of the problem is also grey number since the parameters in the model (27) are grey. 


$$
\begin{aligned}
& f^{*}(\otimes)=\left[f_{-}^{*}, \bar{f}^{*}\right] \\
& x_{i j}(\otimes)=\left[\underline{x}_{i j}, \bar{x}_{i j}\right]
\end{aligned}
$$

The aim of GLP is to obtain grey objective function $f^{*}(\otimes)$, and grey decision variables $x_{i j}(\otimes)$ of model (27) as uncertain interval outputs. In other words, the aim is to find the lower and upper limits for optimal objective function, when the input parameters are grey.

Since the proposed production-inventory problems are unconstrained nonlinear optimization problem, we turn our attention to grey nonlinear programming (GNLP). Let us $X=\left(x_{1}, x_{2}, \ldots, x_{n}\right)$ is decision vector, and $(\otimes)$ a set of grey parameters. Then,

$$
\max Z=f(X, \otimes)
$$

is a grey unconstrained nonlinear programming problem, where $f(X, \otimes)$ is a grey functional. If all grey elements in $f(X, \otimes)$ are whitened then a programming problem is resulted called a whitenized programming as:

$$
\max Z=\tilde{f}(X, \tilde{\otimes})
$$

That is, for grey nonlinear programming problems, we can first whitenize the original problem and then solve the resulted one for the solution. Let us consider that $f(X)$ is a differentiable function. Then, the solution of the gradient vector is a solution of optimization problem;

$$
\frac{\partial \tilde{f}(X, \tilde{\otimes})}{\partial X}=\left(\frac{\partial \tilde{f}(X, \tilde{\otimes})}{\partial x_{1}}, \frac{\partial \tilde{f}(X, \tilde{\otimes})}{\partial x_{2}}, \ldots, \frac{\partial f \tilde{f}(X, \tilde{\otimes})}{\partial x_{n}}\right)=0
$$

If $f(X)$ is second-order differentiable, and its Hessian matrix; 


$$
H(x)=\left(\begin{array}{llll}
\frac{\partial^{2} \tilde{f}(X, \tilde{\otimes})}{\partial x_{1}^{2}} & \frac{\partial^{2} \tilde{f}(X, \tilde{\otimes})}{\partial x_{1} x_{2}} & \cdots & \frac{\partial^{2} \tilde{f}(X, \tilde{\otimes})}{\partial x_{1} x_{n}} \\
\frac{\partial^{2} \tilde{f}(X, \tilde{\otimes})}{\partial x_{2} x_{1}} & \frac{\partial^{2} \tilde{f}(X, \tilde{\otimes})}{\partial x_{2}^{2}} & \cdots & \frac{\partial^{2} \tilde{f}(X, \tilde{\otimes})}{\partial x_{2} x_{n}} \\
\vdots & \vdots & \vdots \\
\frac{\partial^{2} \tilde{f}(X, \tilde{\otimes})}{\partial x_{n} x_{1}} & \frac{\partial^{2} \tilde{f}(X, \tilde{\otimes})}{\partial x_{n} x_{2}} & \cdots & \frac{\partial^{2} \tilde{f}(X, \tilde{\otimes})}{\partial x_{n}^{2}}
\end{array}\right)
$$

is a negative definite matrix. Moreover, in order to reach the lower and upper limits for optimal objective function, the following mathematical models are constructed.

$$
\min _{\gamma} f_{-}(\otimes)=\max _{X} \tilde{f}(X, \tilde{\otimes})
$$

subject to

$$
\begin{gathered}
\tilde{\otimes}=\gamma \bar{\otimes}+(1-\gamma) \underline{\otimes} \\
0 \leq \gamma \leq 1 \\
\max _{\gamma} \bar{f}(\otimes)=\max _{X} \tilde{f}(X, \tilde{\otimes})
\end{gathered}
$$

subject to

$$
\begin{gathered}
\tilde{\otimes}=\gamma \bar{\otimes}+(1-\gamma) \underline{\otimes} \\
0 \leq \gamma \leq 1
\end{gathered}
$$

where $f_{-}(\otimes)$ and $\bar{f}(\otimes)$ represents the lower and upper limits of objective function (total profit per unit time) as grey number. The aim, in grey programming, is to recognize the lower and upper limits of the objective function, $f(X, \otimes)$, caused by grey input parameters.

\section{Grey Modeling}

\subsection{Single Stage Manufacturing System}


In this section, a single stage manufacturing system with the aim of satisfying an external demand $D^{S}$ will be discussed and proposed. In this system, the production is performed through a finite rate $P^{s}{ }_{1}$ based on an EPQ structure. The demand rate is constant, the shortage is not permitted and the purchase cost is assumed to be fixed. Unlike to classical inventory problems, the production process supposed to be defective and a percentage of items $\beta^{S}(\otimes)$ is imperfect. That means defective rate of the system is a grey number $G(\otimes)$ which is defined as an interval with known lower limit upperand known $\underline{\beta}^{s}$ limit $\bar{\beta}^{s}$ as $\quad \beta^{s}(\otimes)=\left[\underline{\beta}^{s}, \bar{\beta}^{s}\right]$. The imperfect items are also under rework process to become perfect and return to consumption cycle. Every cycle of inventory, in our problem, includes periods of (i) production, (ii) reworking and (iii) depletion. A percentage of defective items $\beta^{s}(\otimes)$ is produced during the production period, and then a rework process with rate $P^{S}{ }_{2}$ will be started. The environmental effects, in real situations, result in unsuitable variations in the quality of products. So, the percentage of defective items $\beta^{S}(\otimes)$ is assumed to be a random variable. During the production interval $t_{p}^{S}$, the products are produced by a rate $P^{S}{ }_{1}$. At the end of the production period, there are imperfect items whose amount are determined by multiplying defective rate and production quantity, i.e., $\beta^{S}(\otimes) Q^{S}$.At this moment, the rework process commences for the reworkable items $\alpha \beta^{S}(\otimes) Q^{S}$ - The scrapped items $(1-\alpha) \beta^{S}(\otimes) Q^{S}$ are detected and disposed. The reworkable items $\alpha \beta^{S}(\otimes) Q^{S}$ go under reworking, become perfect items and then return to perfect items stock. During depletion period $t_{D}$, the stored inventory is fully consumed. At every cycle, this process repeats without interruption. To ensure feasibility and prevent shortage, we consider the initial condition as $I_{\text {max }}^{S}-\alpha \beta^{S}(\otimes) Q^{S} \geq 0$. Since $I^{S}{ }_{\text {max }}=Q^{S}\left(1-D^{S} / P^{S}{ }_{1}\right)$, this condition simplifies to $\beta^{S}(\otimes) \leq 1-D / P_{1}$. Therefore, defective rate $\beta(\otimes)$ is 
assumed to be a variable on interval $\left[0,1-D^{S} / P^{S}{ }_{1}\right]$, to avoid shortage and ensure feasibility. In order to maximize the total profit, we seek the optimal production quantity $\mathrm{Q}^{S}$. The total profit $T P^{S}$ is subtraction of total cost $T C^{S}$ from total revenue $T R^{S}$. The total revenue per cycle $T R$ involves sales of perfect and scrapped items which is given as $T R^{s}=v^{s}\left\{Q^{s}-\beta^{S}(\otimes) \mathrm{Q}^{S}+\alpha \beta^{S}(\otimes) \mathrm{Q}^{S}\right\}+s^{s}\left\{(1-\alpha) \beta^{S}(\otimes) \mathrm{Q}^{S}\right\}$ where $\quad v^{s} \quad$ and $\quad s^{s}$ represent the sale price of perfect and scrapped items respectively for a single-stage system. The total cost involves production, setup, holding, screening and reworking costs. The production cost $P C^{S}$ can be determined by $P C^{S}=C^{S} Q^{S}$, and the setup cost $S C^{S}$ is calculated by $S C^{S}=A^{S}$. We should calculate the area below the inventory curve in order to compute the holding cost. To this end, we name areas below first period production $S_{I}{ }^{s}$, second rework period $S_{I I}{ }^{s}$ and third depletion period $S_{I I I}{ }^{s}$. By doing so, we reach $S_{I}^{S}=\frac{Q^{S 2}}{2 P_{1}^{S}}\left(1-D^{S} / P_{1}^{S}\right)$, $S_{I I}^{S}=\frac{\alpha \beta^{S}(\otimes) \mathrm{Q}^{S}}{2 P^{S}{ }_{2}}\left\{2 Q^{S}\left(1-D^{S} / P^{S}{ }_{1}\right)-2 \beta^{S}(\otimes) \mathrm{Q}^{S}+\alpha \beta^{S}(\otimes) \mathrm{Q}^{S}\left(1-D^{S} / P^{S}{ }_{2}\right)\right\}$, and $S^{S}{ }_{I I I}=\frac{1}{2 D^{S}}\left\{Q^{S}\left(1-D^{S} / P^{S}{ }_{1}\right)-\beta^{S}(\otimes) \mathrm{Q}^{S}+\alpha \beta^{S}(\otimes) \mathrm{Q}^{S}\left(1-D^{S} / P^{S}\right)\right\}^{2}$. Then the holding cost can be computed as follows.

$$
H C^{S}=h^{S} Q^{S 2}\left\{\frac{G^{S 2}(\otimes)}{2 D^{S}}+\frac{1}{2 P_{1}^{S}}\left(1-\frac{D^{S}}{P_{1}^{S}}\right)+\frac{\alpha \beta^{S}(\otimes)}{2 P_{2}^{S}}\left\{\left(1-\frac{D^{S}}{P_{1}^{S}}\right)-\beta^{S}(\otimes)+G^{S}(\otimes)\right\}\right\}
$$

Where $h$ is the unit holding cost (per product per unit time), and $G^{S}(\otimes)=\left(1-\frac{D^{S}}{P_{1}^{S}}\right)-\beta^{S}(\otimes)+\alpha \beta^{S}(\otimes)\left(1-\frac{D^{S}}{P_{2}^{S}}\right)$. Moreover, the cost of screening is calculated by $W C^{S}=d^{S} Q^{S}$ where $d$ is the unit screening cost per item. In 
addition, the reworking cost is formulated as $R C^{S}=r^{S} \alpha \beta^{S}(\otimes) Q^{S}$ in which $r^{S}$ is the cost of rework item.

By using above formulation, the total cost can be written as follows.

$$
T C^{S}=C^{S} Q^{S}+A^{S}+h^{S} Q^{S 2}\left\{\frac{G^{S 2}(\otimes)}{2 D^{S}}+\frac{1}{2 P_{1}^{S}}\left(1-\frac{D^{S}}{P^{S}{ }_{1}}\right)+\frac{\alpha \beta^{S}(\otimes)}{2 P^{S}{ }_{2}}\left\{\left(1-\frac{D^{S}}{P^{S}{ }_{1}}\right)-\beta^{S}(\otimes)+G^{S}(\otimes)\right\}\right\}+d^{S} Q^{S}
$$

Therefore, the total profit can be calculated by $T R^{S}-T C^{S}$ as:

$$
\begin{gathered}
T P^{S}=v^{S}\left\{Q^{S}-\beta^{S}(\otimes) \mathrm{Q}^{S}+\alpha \beta^{S}(\otimes) \mathrm{Q}^{S}\right\}+s^{S}\left\{(1-\alpha) \beta^{S}(\otimes) \mathrm{Q}^{S}\right\}-C^{S} Q^{S}-A^{S} \\
-h^{S} Q^{S 2}\left\{\frac{G^{S 2}(\otimes)}{2 D^{S}}+\frac{1}{2 P^{S}}\left(1-\frac{D^{S}}{P_{1}^{S}}\right)+\frac{\alpha \beta^{S}(\otimes)}{2 P^{S}}\left\{\left(1-\frac{D^{S}}{P^{S}}\right)-\beta^{S}(\otimes)+G^{S}(\otimes)\right\}\right\} \\
-d^{S} Q^{S}-r^{S} \alpha \beta^{S}(\otimes) \mathrm{Q}^{S}
\end{gathered}
$$

Since the defective rate is a grey number, then the whitened value of total profit, $T \tilde{P}^{S}(\otimes)$, is given by substituting the whitened value of defective rate $\tilde{\beta}(\otimes)$ into the above formula, as follows:

$$
\begin{gathered}
T \tilde{P}^{S}(\otimes)=v^{S}\left\{Q^{S}-\tilde{\beta}^{S}(\otimes) \mathrm{Q}^{S}+\alpha \tilde{\beta}^{S}(\otimes) \mathrm{Q}^{S}\right\}+s^{S}\left\{(1-\alpha) \tilde{\beta}^{S}(\otimes) \mathrm{Q}^{S}\right\}-C^{S} Q^{S}-A^{S} \\
-h^{S} Q^{S 2}\left\{\frac{\tilde{G}^{S 2}(\otimes)}{2 D^{S}}+\frac{1}{2 P^{S}{ }_{1}}\left(1-\frac{D^{S}}{P^{S}{ }_{1}}\right)+\frac{\alpha \tilde{\beta}^{S}(\otimes)}{2 P^{S}}\left\{\left(1-\frac{D^{S}}{P^{S}}\right)-\tilde{\beta}^{S}(\otimes)+\tilde{G}^{S}(\otimes)\right\}\right\} \\
-d^{S} Q^{S}-r^{S} \alpha \tilde{\beta}^{S}(\otimes) \mathrm{Q}^{S}
\end{gathered}
$$


Where $\tilde{G}^{S}(\otimes)$ is $\left(1-\frac{D^{S}}{P^{S}}\right)-\tilde{\beta}^{S}(\otimes)+\alpha \tilde{\beta}^{S}(\otimes)\left(1-\frac{D^{S}}{P_{2}^{S}}\right)$. Moreover, the whitened value of total profit per unit time $T \tilde{P} U^{S}(\otimes)$ can be computed by dividing $T \tilde{P}^{S}(\otimes)$ by whitened inventory cycle time $\tilde{T}^{S}(\otimes)$. In another way, the cycle time is $t^{S}{ }_{P}+t^{S}{ }_{R}+t^{S}{ }_{D}$ which simplifies to $\quad \tilde{T}^{S}(\otimes)=\frac{Q}{D}\left(\tilde{\beta}^{S}(\otimes)(\alpha-1)+1\right)$.

Therefore, the whitened total profit per unit time $T \tilde{P} U^{S}(\otimes)$ is calculated:

$$
\begin{gathered}
T \tilde{P} U^{S}(\otimes)=\frac{D^{S}}{\tilde{\beta}^{S}(\otimes)(\alpha-1)+1} \\
\left\{v^{S}\left\{\tilde{\beta}^{S}(\otimes)(\alpha-1)+1\right\}+s^{s}\left\{(1-\alpha) \tilde{\beta}^{S}(\otimes)\right\}-C^{S}-h^{S} Q^{S}\left\{\frac{\tilde{G}^{S}(\otimes)^{2}}{2 D^{S}}+\frac{1}{2 P_{1}^{S}}\left(1-\frac{D^{S}}{P_{1}}\right)+\frac{\alpha \tilde{\beta}^{S}(\otimes)}{2 P_{2}^{S}}\left\{\left(1-\frac{D^{S}}{P_{1}^{S}}\right)\right.\right.\right. \\
\quad-\frac{A^{S} D^{S}}{Q^{S}\left(\tilde{\beta}^{S}(\otimes)(\alpha-1)+1\right)}
\end{gathered}
$$

It can be proved that $T \tilde{P} U^{S}(\otimes)$ is a concave function of $Q^{S}$, since second derivative is negative. Therefore, in order to obtain the optimal quantity $Q^{S^{*}}$ , we set the first derivative to zero, and reached to:

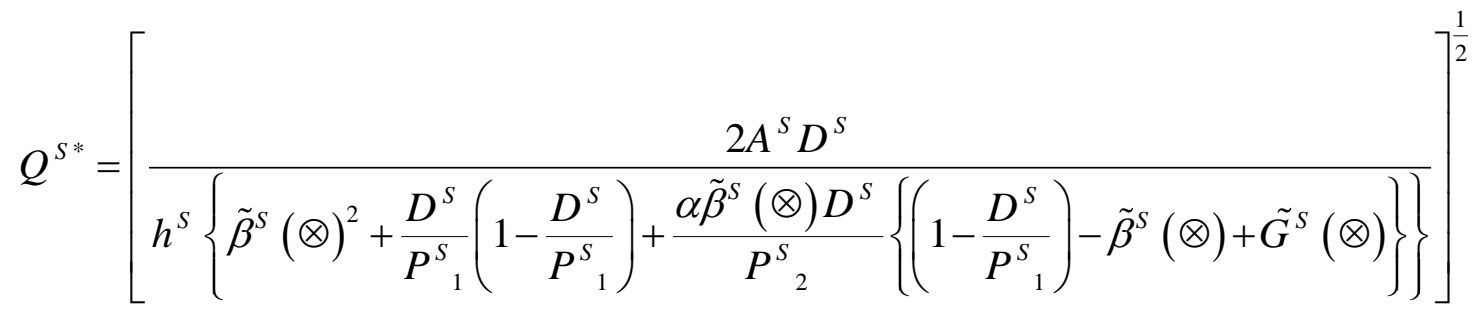

Note that when $\tilde{\beta}^{S}(\otimes)=0, Q^{S *}$ reduces to the traditional EPQ formula, $\left[2 A^{S} D^{S} /\left(h^{S}\left(1-\frac{D^{S}}{P^{S}}\right)\right)\right]_{1}^{1 / 2}$.

Moreover, in order to reach the lower and upper limits for optimal objective function, the following mathematical models are constructed. 


$$
\min _{\gamma} \underline{T P U^{S}}(\otimes)=\max _{Q^{S}{ }_{1}} T \tilde{P} U^{S}(\otimes)
$$

subject to

$$
\begin{gathered}
\tilde{\beta}^{S}(\otimes)=\gamma \bar{\beta}^{S}+(1-\gamma) \underline{\beta}^{S} \\
0 \leq \gamma \leq 1 \\
\max _{\gamma} \overline{T P U^{S}}(\otimes)=\max _{Q^{S}} T \tilde{P} U^{S}(\otimes)
\end{gathered}
$$

subject to

$$
\begin{gathered}
\tilde{\beta}^{S}(\otimes)=\gamma \bar{\beta}^{S}+(1-\gamma) \underline{\beta}^{S} \\
0 \leq \gamma \leq 1
\end{gathered}
$$

where $\underline{T P U^{S}}(\otimes)$ and $\overline{T P U^{S}}(\otimes)$ represents the lower and upper limits of the objective function (total profit per unit time) as grey number. It is notable that the existence of the grey defective rate leads that the total profit is also a grey number with upper and lower limits. The aim, in grey programming, is to recognize the lower and upper limits of the objective function, TPU in our model, caused by grey input parameters. This will be obtained in our model by GP model. In addition, note that the first model is a minimax problem (can be solved via conventional minimax commands in Matlab), while the second one is a maximization problem with two variables $Q_{1}$ and $\gamma$ (can be simply solved by nonlinear optimization commands in Matlab).

\subsection{Multi Stage Manufacturing System}

In this section, we extend the single stage manufacturing system introduced in the previous section to a multi-stage one. Let's consider an imperfect $n$ stage manufacturing system with serial arrangement. As shown in Figure 1, each production stage $j$ performs a specific operation on input items via production rate $P_{1 j}$ and then send the perfect output items into next manufacturing stage $j+1$. Moreover, the stage $j$ is assumed to be defective 
and produces some percentages of imperfect items $\beta_{j}(\otimes)$. Similar to single stage case, the percentages of imperfect items $\beta_{j}(\otimes)$ is also a grey number whose lower and upper limits. The defective items which are reworkable go under rework process with rework rate $P_{2 j}$. At the end of rework period, the stored inventory is sent to next production stage $j+1$ for further processing. At each stage, there are three types of output items: (i) perfect items, (ii) imperfect but reworkable items, and (iii) imperfect and scrapped items. Once the production ends, there exist imperfect items $\beta_{j}(\otimes) Q_{j}$. Among them, the reworkable items $\alpha_{j} \beta_{j}(\otimes) Q_{j}$ go under reworking process and the scrapped items $\left(1-\alpha_{j}\right) \beta_{j}(\otimes) Q_{j}$ are disposed from the system. During rework period $t_{R j}$ , all the reworkable items $\alpha_{j} \beta_{j}(\otimes) Q_{j}$ become perfect with the rate of $P_{2 j}$ and return to the system. At the end of rework period, the stored inventory is transferred into next stage. The prefect and reworked items are sent to the next production stages for further processing. This is continued till the items reach to $n$th production stage. This stage is different from previous intermediate stages. It has one more period than previous stages, i.e., the depletion period. At this stage, the finished products are produced and are then depleted via demand rate $D$. Indeed, at the end of rework period, the stored inventory is consumed during depletion period $t_{D}$ till reach to zero. Figure 2 presents the inventory level of $n$th (final) production stage. The aim is to determine optimal/economic production quantities $Q_{1}, Q_{2}, \ldots, Q_{n}$, in such a way that the total profit is maximized. Moreover, Figure 3 depicts the inventory level of the entire planning horizon. To ensure feasibility and avoid shortage during stage $j$, the inventory level at the start of the rework period of every stage $j$ should be greater/equal than zero. For this purpose, we should have $P_{1 j} Q_{j}-\beta_{j}(\otimes) Q_{j} \geq 0$, which simplifies to $\beta_{j}(\otimes) \leq P_{1 j}$ for $j=1,2, \ldots, n$. 
Before formulating total profit, we derive relationship between production quantities $Q_{1}, Q_{2}, \ldots, Q_{n}$. The production quantity at next stage $Q_{j+1}$ is sum of perfect items produced at the current stage $Q_{j}-\beta_{j}(\otimes) Q_{j}$ and reworked items at current stage $\alpha_{j} \beta_{j}(\otimes) Q_{j}$, which is simplified to:

$$
Q_{j+1}=Q_{j}\left\{\beta_{j}(\otimes)\left(\alpha_{j}-1\right)+1\right\} \quad \forall j=1,2, \ldots, n-1
$$

For simplicity, we consider $Q_{1}$ as a decision variable in our model, and formulate production quantity $Q_{j}(j \neq 1)$ in terms of $Q_{1}$, using the above recursive equation, as follows.

$$
Q_{1} \prod_{p=1}^{j-1}\left\{\beta_{p}(\otimes)\left(\alpha_{p}-1\right)+1\right\} \quad \forall j=2,3, \ldots, n
$$

The total revenue per cycle $T R$ involves sales of perfect and scrapped items which is given as $T R^{M}=v\left\{Q_{n}-\beta_{n}(\otimes) Q_{n}+\alpha_{n} \beta_{n}(\otimes) Q_{n}\right\}+\sum_{j=1}^{n}\left\{s_{j}\left(1-\alpha_{j}\right) \beta_{j}(\otimes) Q_{j}\right\}$ where $v$ denotes the unit sale price of perfect items and $s_{j}$ represents the unit sale price for scrapped items at stage $j$. By substituting $Q_{n}$ and $Q_{j}$ from Eq. 25into $T R^{M}$, it can be re-written in terms of decision variable $Q_{1}$ as follows.

$$
T R^{M}=v Q_{1} \prod_{j=1}^{n}\left\{\beta_{j}(\otimes)\left(\alpha_{j}-1\right)+1\right\}+s_{1}\left(1-\alpha_{1}\right) \beta_{1}(\otimes) Q_{1}+\left(\sum_{j=2}^{n}\left\{s_{j}\left(1-\alpha_{j}\right) \beta_{j}(\square) \prod_{p=1}^{j-1}\left\{\beta_{p(26)}(26)\left(\alpha_{p}-1\right)+1\right\}\right\}\right.
$$

The total cost involves production, setup, holding, screening and reworking costs. The production cost per cycle $P C^{M}$ is calculated as $P C^{M}=\sum_{j=1}^{n} C_{j} Q_{j}$ which is re-written as: 


$$
P C^{M}=C_{1} Q_{1}+\left(\sum_{j=2}^{n} C_{j} \prod_{p=1}^{j-1}\left\{\beta_{p}(\otimes)\left(\alpha_{p}-1\right)+1\right\}\right) Q_{1}
$$

addition, the setup cost $S C^{M}$ is incurred per production cycle by $S C^{M}=\sum_{j=1}^{n} A_{j}$. Moreover, in order to calculate the holding cost, we first calculate the area below the inventory level in two periods, i.e., production period $S_{I j}$ and rework period $S_{I j}$. The first area is calculated as $S_{I j}=I_{\text {maxj }} t_{p j} / 2$ . Since $I_{\text {maxj }}=Q_{j}$. and $t_{p j}=Q_{j} / P_{1 j}$, the $S_{l j}$ is re-written as.

$$
S_{I j}=\frac{Q_{j}^{2}}{2 P_{1 j}}
$$

To calculate $S_{I j}$, we should first formulate the inventory level at the start of rework period $I_{1 j}$ and the inventory level at the end of the rework period $I_{2 j}$. , as $I_{1 j}=Q_{j}-\beta_{j}(\otimes) Q_{j}$ and $I_{2 j}=Q_{j}-\beta_{j}(\otimes) Q_{j}+P_{2 j} t_{R j}$. Similar to single stage case, we can calculate rework period of stage $j$ as $t_{R j}=\alpha_{j} \beta_{j}(\otimes) Q_{j} / P_{2 j}$. So the inventory level $I_{2 j}$ can be simplified as $I_{2 j}=Q_{j}-\beta_{j}(\otimes) Q_{j}+\alpha_{j} \beta_{j}(\otimes) Q_{j}$. Therefore, the area below the inventory level in rework period is calculated as $S_{I I j}=t_{R j}\left(I_{1 j}+I_{2 j}\right) / 2$ which can be re-written as:

$$
S_{I j}=\frac{\alpha_{j} \beta_{j}(\otimes) Q_{j}}{2 P_{2 j}}\left\{2 Q_{j}-2 \beta_{j}(\otimes) Q_{j}+\alpha_{j} \beta_{j}(\otimes) Q_{j}\right\}
$$

In addition to production and rework periods, there is one depletion period in $n$th (final) period. Therefore, the area below the inventory level in depletion period is calculated as $S_{I I I}=I_{2 n} t_{D} / 2$ where the depletion period is $t_{D}=I_{2 n} / D$, hence, we have $S_{I I I}=I_{2 n}^{2} / 2 D$ which is re-written as.

$$
S_{I I I}=\frac{Q_{n}^{2}}{2 D}\left\{1-\beta_{n}(\otimes)+\alpha_{n} \beta_{n}(\otimes)\right\}^{2}
$$


Utilizing $S_{I j}, S_{I I}$ and $S_{I I I}$, the holding cost is calculated by $\sum_{j=1}^{n} h_{j}\left\{S_{I j}+S_{I I j}\right\}+h_{n} S_{I I I}$, as follows.

$$
H C^{M}=\sum_{j=1}^{n} h_{j}\left\{\frac{Q_{j}^{2}}{2 P_{1 j}}+\frac{\alpha_{j} \beta_{j}(\otimes) Q_{j}}{2 P_{2 j}}\left\{2 Q_{j}-2 \beta_{j}(\otimes) Q_{j}+\alpha_{j} \beta_{j}(\otimes) Q_{j}\right\}\right\}+h_{n} \frac{Q_{n}^{2}}{2 D}\left\{1-\beta_{n}(\otimes)+\alpha_{n} \beta_{n}(\otimes)\right\}^{2}
$$

By substituting $Q_{n}$ and $Q_{j}$ from Eq. 25into $H C$, it can be re-written in terms of decision variable $Q_{1}$ as follows.

$$
\begin{gathered}
H C^{M}=h_{1} Q_{1}^{2}\left\{\frac{1}{2 P_{11}}+\frac{\alpha_{1} \beta_{1}(\otimes)}{2 P_{21}}\left\{2-2 \beta_{1}(\otimes)+\alpha_{1} \beta_{1}(\otimes)\right\}\right\} \\
+\sum_{j=2}^{n}\left\{h_{j} Q_{1}^{2}\left(\prod_{p=1}^{j-1}\left\{\beta_{p}(\otimes)\left(\alpha_{p}-1\right)+1\right\}\right)^{2}\left\{\frac{1}{2 P_{1 j}}+\frac{\alpha_{j} \beta_{j}(\otimes)}{2 P_{2 j}}\left\{2-2 \beta_{j}(\otimes)+\alpha_{j} \beta_{j}(\otimes)\right\}\right\}\right\} \\
+h_{n} \frac{Q_{1}^{2}}{2 D}\left(\prod_{p=1}^{n-1}\left\{\beta_{p}(\otimes)\left(\alpha_{p}-1\right)+1\right\}\right)^{2}\left\{1-\beta_{n}(\otimes)+\alpha_{n} \beta_{n}(\otimes)\right\}^{2}
\end{gathered}
$$

The screening cost per cycle $W C$ is computed as $W C^{M}=\sum_{j=1}^{n} d_{j} Q_{j}$ which $d_{j}$ represents the screening cost per item in stage $j$. Moreover, the reworking cost per cycle $R C$ is obtained $R C=\sum_{j=1}^{n} r_{j} \alpha_{j} \beta_{j}(\otimes) Q_{j}$ where $r_{j}$ denotes the rework cost per item in stage $j$. By using $Q_{j}$ from Eq. 25, screening and rework costs are re-written in terms of decision variable $Q_{1}$ as follows.

$$
\begin{gathered}
W C^{M}=d_{1} Q_{1}+Q_{1} \sum_{j=2}^{n}\left(d_{j} \prod_{p=1}^{j-1}\left\{\beta_{p}(\otimes)\left(\alpha_{p}-1\right)+1\right\}\right) \\
R C^{M}=r_{1} \alpha_{1} \beta_{1}(\otimes) Q_{1}+Q_{1} \sum_{j=2}^{n}\left(r_{j} \alpha_{j} \beta_{j}(\otimes) \prod_{p=1}^{j-1}\left\{\beta_{p}(\otimes)\left(\alpha_{p}-1\right)+1\right\}\right)
\end{gathered}
$$

Therefore, the total cost per cycle is obtained by $P C^{M}+S C^{M}+H C^{M}+W C^{M}+R C^{M}$ as follows. 


$$
\begin{gathered}
T C^{M}=C_{1} Q_{1}+\left(\sum_{j=2}^{n} C_{j} \prod_{p=1}^{j-1}\left\{\beta_{p}(\otimes)\left(\alpha_{p}-1\right)+1\right\}\right) Q_{1}+ \\
\sum_{j=1}^{n} A_{j}+h_{1} Q_{1}^{2}\left\{\frac{1}{2 P_{11}}+\frac{\alpha_{1} \beta_{1}(\otimes)}{2 P_{21}}\left\{2-2 \beta_{1}(\otimes)+\alpha_{1} \beta_{1}(\otimes)\right\}\right\}+\sum_{j=2}^{n}\left\{h _ { j } Q _ { 1 } ^ { 2 } ( \prod _ { p = 1 } ^ { j - 1 } \{ \beta _ { p } ( \otimes ) ( \alpha _ { p } - 1 ) + 1 \} ) ^ { 2 } \left\{\frac{1}{2 P_{1 j}}+\right.\right. \\
+h_{n} \frac{Q_{1}^{2}}{2 D}\left(\prod_{p=1}^{n-1}\left\{\beta_{p}(\otimes)\left(\alpha_{p}-1\right)+1\right\}\right)^{2}\left\{1-\beta_{n}(\otimes)+\alpha_{n} \beta_{n}(\otimes)\right\}^{2}+d_{1} Q_{1} \\
+Q_{1} \sum_{j=2}^{n}\left(d_{j} \prod_{p=1}^{j-1}\left\{\beta_{p}(\otimes)\left(\alpha_{p}-1\right)+1\right\}\right)-r_{1} \alpha_{1} \beta_{1}(\otimes) Q_{1} \\
-Q_{1} \sum_{j=2}^{n}\left(r_{j} \alpha_{j} \beta_{j}(\otimes) \prod_{p=1}^{j-1}\left\{\beta_{p}(\otimes)\left(\alpha_{p}-1\right)+1\right\}\right)
\end{gathered}
$$

Here, the total profit per cycle $T P^{M}$ can be calculated by $T R^{M}-T C^{M}$ as follows.

$$
\begin{gathered}
T P^{M}=v Q_{1} \prod_{j=1}^{n}\left\{\beta_{j}(\otimes)\left(\alpha_{j}-1\right)+1\right\}+s_{1}\left(1-\alpha_{1}\right) \beta_{1}(\otimes) Q_{1} \\
+\left(\sum_{j=2}^{n}\left\{s_{j}\left(1-\alpha_{j}\right) \beta_{j}(\otimes) \prod_{p=1}^{j-1}\left\{\beta_{p}(\otimes)\left(\alpha_{p}-1\right)+1\right\}\right\}\right) Q_{1}-C_{1} Q_{1} \\
-\left(\sum_{j=2}^{n} C_{j} \prod_{p=1}^{j-1}\left\{\beta_{p} \otimes\left(\alpha_{p}-1\right)+1\right\}\right) Q_{1}-\sum_{j=1}^{n} A_{j} \\
-h_{1} Q_{1}^{2}\left\{\frac{1}{2 P_{11}}+\frac{\alpha_{1} \beta_{1}(\otimes)}{2 P_{21}}\left\{2-2 \beta_{1}(\otimes)+\alpha_{1} \beta_{1}(\otimes)\right\}\right\} \\
-\sum_{j=2}^{n}\left\{h_{j} Q_{1}^{2}\left(\prod_{p=1}^{j-1}\left\{\beta_{p}(\otimes)\left(\alpha_{p}-1\right)+1\right\}\right)^{2}\left\{\frac{1}{2 P_{1 j}}+\frac{\alpha_{j} \beta_{j}(\otimes)}{2 P_{2 j}}\left\{2-2 \beta_{j}(\otimes)+\alpha_{j} \beta_{j}(\otimes)\right\}\right\}\right\} \\
-h_{n} \frac{Q_{1}^{2}}{2 D}\left(\prod_{p=1}^{n-1}\left\{\beta_{p}(\otimes)\left(\alpha_{p}-1\right)+1\right\}\right)^{2}\left\{1-\beta_{n}(\otimes)+\alpha_{n} \beta_{n}(\otimes)\right\}^{2}-d_{1} Q_{1}-Q_{1} \sum_{j=2}^{n}\left(d_{j} \prod_{p=1}^{j-1}\left\{\beta_{p}(\otimes)\left(\alpha_{p}-1\right)+1\right\}\right) \\
-r_{1} \alpha_{1} \beta_{1}(\otimes) Q_{1}-Q_{1} \sum_{j=2}^{n}\left(r_{j} \alpha_{j} \beta_{j}(\otimes) \prod_{p=1}^{j-1}\left\{\beta_{p}(\otimes)\left(\alpha_{p}-1\right)+1\right\}\right)
\end{gathered}
$$


Since the defective rate is a grey number, then the total profit is also grey whose whitened value is given as:

$$
\begin{aligned}
& T \tilde{P}^{M}(\otimes)=v Q_{1} \prod_{j=1}^{n}\left\{\tilde{\beta}_{j}(\otimes)\left(\alpha_{j}-1\right)+1\right\}+s_{1}\left(1-\alpha_{1}\right) \tilde{\beta}_{1}(\otimes) Q_{1}+\left(\sum _ { j = 2 } ^ { n } \left\{s _ { j } ( 1 - \alpha _ { j } ) \tilde { \beta } _ { j } ( \otimes ) \prod _ { p = 1 } ^ { j - 1 } \left\{\tilde{\beta}_{p}(\otimes)\left(\alpha_{p}-1\right)\right.\right.\right. \\
& -C_{1} Q_{1}-\left(\sum_{j=2}^{n} C_{j} \prod_{p=1}^{j-1}\left\{\tilde{\beta}_{p}(\otimes)\left(\alpha_{p}-1\right)+1\right\}\right) Q_{1}-\sum_{j=1}^{n} A_{j}-h_{1} Q_{1}^{2}\left\{\frac{1}{2 P_{11}}+\frac{\alpha_{1} \tilde{\beta}_{1}(\otimes)}{2 P_{21}}\left\{2-2 \tilde{\beta}_{1}(\otimes)+\alpha_{1} \tilde{\beta}_{1}(\otimes)\right\}\right\} \\
& -\sum_{j=2}^{n}\left\{h_{j} Q_{1}^{2}\left(\prod_{p=1}^{j-1}\left\{\tilde{\beta}_{p}(\otimes)\left(\alpha_{p}-1\right)+1\right\}\right)^{2}\left\{\frac{1}{2 P_{1 j}}+\frac{\alpha_{j} \tilde{\beta}_{j}(\otimes)}{2 P_{2 j}}\left\{2-2 \tilde{\beta}_{j}(\otimes)+\alpha_{j} \tilde{\beta}_{j}(\otimes)\right\}\right\}\right\} \\
& -h_{n} \frac{Q_{1}^{2}}{2 D}\left(\prod_{p=1}^{n-1}\left\{\tilde{\beta}_{p}(\otimes)\left(\alpha_{p}-1\right)+1\right\}\right)^{2}\left\{1-\tilde{\beta}_{n}(\otimes)+\alpha_{n} \tilde{\beta}_{n}(\otimes)\right\}^{2}-d_{1} Q_{1}-Q_{1} \sum_{j=2}^{n}\left(d_{j} \prod_{p=1}^{j-1}\left\{\tilde{\beta}_{p}(\otimes)\left(\alpha_{p}-1\right)+1\right\}\right) \\
& -r_{1} \alpha_{1} \tilde{\beta}_{1}(\otimes) Q_{1}-Q_{1} \sum_{j=2}^{n}\left(r_{j} \alpha_{j} \tilde{\beta}_{j}(\otimes) \prod_{p=1}^{j-1}\left\{\tilde{\beta}_{p}(\otimes)\left(\alpha_{p}-1\right)+1\right\}\right)
\end{aligned}
$$

where $\tilde{\beta}_{j}(\otimes)$ represents the whitened value of defective rate $\tilde{\beta}_{j}(\otimes)$. In addition, the whitened value of total profit per unit time $T \tilde{P} U^{M}(\otimes)$ is calculated by dividing $T \tilde{P}^{M}(\otimes)$ by the whitened cycle time $\tilde{T}^{M}(\otimes)$. The cycle time is formulated as $T^{M}$ which simplifies, by using $t_{P j}=Q_{j} / P_{1 j}, \quad t_{R j}=\alpha_{j} \beta_{j}(\otimes) Q_{j} / P_{2 j} \quad$ and $t_{D}=\frac{Q_{n}}{D}\left\{1-\beta_{n}(\otimes)+\alpha_{n} \beta_{n}(\otimes)\right\}$, to:

$$
T^{M}(\otimes)=\sum_{j=1}^{n} \frac{Q_{j}}{P_{1 j}}+\sum_{j=1}^{n} \frac{\alpha_{j} \beta_{j}(\otimes) Q_{j}}{P_{2 j}}+\frac{Q_{n}}{D}\left\{1-\beta_{n}(\otimes)+\alpha_{n} \beta_{n}(\otimes)\right\}
$$

By using $Q_{j}$ from Eq. 25, cycle time $T^{M}(\otimes)$ is re-written in terms of variable $Q_{1}$ as follows. 


$$
\begin{aligned}
T^{M}(\otimes)=\frac{Q_{1}}{P_{11}}+\sum_{j=2}^{n}\left(\frac{Q_{1}}{P_{1 j}} \prod_{p=1}^{j-1}\left\{\beta_{p}(\otimes)\left(\alpha_{p}-1\right)+1\right\}\right)+\frac{\alpha_{1} \beta_{1}(\otimes) Q_{1}}{P_{21}}+\sum_{j=2}^{n}\left(\frac { \alpha _ { j } \beta _ { j } ( \otimes ) Q _ { 1 } } { P _ { 2 j } } \prod _ { p = 1 } ^ { j - 1 } \left\{\beta_{p}(\otimes)\left(\alpha_{p}-1\right)+\right.\right. \\
+\frac{Q_{1}}{D}\left(\prod_{p=1}^{n-1}\left\{\beta_{p}(\otimes)\left(\alpha_{p}-1\right)+1\right\}\right)\left\{1-\beta_{n}(\otimes)+\alpha_{n} \beta_{n}(\otimes)\right\}
\end{aligned}
$$

The cycle time $T^{M}(\otimes)$ is also a grey number, and then the whitened cycle time is calculated as

$$
\begin{gathered}
\tilde{T}^{M}(\otimes)=\frac{Q_{1}}{P_{11}}+\sum_{j=2}^{n}\left(\frac{Q_{1}}{P_{1 j}} \prod_{p=1}^{j-1}\left\{\tilde{\beta}_{p}(\otimes)\left(\alpha_{p}-1\right)+1\right\}\right)+\frac{\alpha_{1} \tilde{\beta}_{1}(\otimes) Q_{1}}{P_{21}}+\sum_{j=2}^{n}\left(\frac{\alpha_{j} \tilde{\beta}_{j}(\otimes) Q_{1}}{P_{2 j}} \prod_{p=1}^{j-1}\left(4 \beta_{p}\right)(\otimes)\left(\alpha_{p}-1\right)+\right. \\
+\frac{Q_{1}}{D}\left(\prod_{p=1}^{n}\left\{\tilde{\beta}_{p}(\otimes)\left(\alpha_{p}-1\right)+1\right\}\right)
\end{gathered}
$$

For simplicity, we define $F_{j}=\tilde{\beta}_{j}(\otimes)\left(\alpha_{j}-1\right)+1$ for $2 \leq j \leq n$, hereafter. Therefore, the whitened value of total profit per unit time $T \tilde{P} U^{M}(\otimes)=T \tilde{P}^{M}(\otimes) / \tilde{T}^{M}(\otimes)$ is obtained:

$$
\begin{gathered}
T \tilde{P U}^{M}(\otimes)=\left\{v \prod_{j=1}^{n} F_{j}+s_{1}\left(1-\alpha_{1}\right) \tilde{\beta}_{1}(\otimes)+\left(\sum_{j=2}^{n}\left\{s_{j}\left(1-\alpha_{j}\right) \tilde{\beta}_{j}(\otimes) \prod_{p=1}^{j-1} F_{p}\right\}\right)-C_{1}-\left(\sum_{j=2}^{n} C_{j} \prod_{p=1}^{j-1} F_{p}\right)-\left(\frac{\sum_{j=1}^{n}}{Q_{1}}\right.\right. \\
-h_{1} Q_{1}\left\{\frac{1}{2 P_{11}}+\frac{\alpha_{1} \tilde{\beta}_{1}(\otimes)}{2 P_{21}}\left\{1-\tilde{\beta}_{1}(\otimes)+F_{1}\right\}\right\}-\sum_{j=2}^{n} h_{j}\left\{Q_{1}\left(\prod_{p=1}^{j-1} F_{p}\right)^{2}\left\{\frac{1}{2 P_{1 j}}+\frac{\alpha_{j} \tilde{\beta}_{j}(\otimes)}{2 P_{2 j}}\left\{1-\tilde{\beta}_{j}(\otimes)+F_{j}\right\}\right\}\right\} \\
\left.-h_{n} \frac{Q_{1} F_{n}^{2}}{2 D}\left(\prod_{p=1}^{n-1} F_{p}\right)^{2}-d_{1}-\sum_{j=2}^{n}\left(d_{j} \prod_{p=1}^{j-1} F_{p}\right)-r_{1} \alpha_{1} \tilde{\beta}_{1}(\otimes)-\sum_{j=2}^{n}\left(r_{j} \alpha_{j} \tilde{\beta}_{j}(\otimes) \prod_{p=1}^{j-1} F_{p}\right)\right\} \\
\quad\left\{\frac{1}{P_{11}}+\sum_{j=2}^{n}\left(\frac{1}{P_{1 j}} \prod_{p=1}^{j-1} F_{p}\right)+\frac{\alpha_{1} \tilde{\beta}_{1}(\otimes)}{P_{21}}+\sum_{j=2}^{n}\left(\frac{\alpha_{j} \tilde{\beta}_{j}(\otimes)}{P_{2 j}} \prod_{p=1}^{j-1} F_{p}\right)+\frac{1}{D} \prod_{p=1}^{n} F_{p}\right\}
\end{gathered}
$$

It can be shown that the derived total profit per unit time $T \tilde{P} U^{M}(\otimes)$ is concave with respect to decision variable $Q_{1}$, since $\frac{\partial^{2} T \tilde{P} U^{M}(\otimes)}{\partial Q_{1}^{2}} \leq 0$. Therefore, in order 
to reach the economic production quantity $Q_{1}^{*}$, we set the first derivative of $T \tilde{P} U^{M}(\otimes)$ to zero, which results:

$Q_{1}^{*}=\left[\frac{2\left(\sum_{j=1}^{n} A_{j}\right) D}{h_{1} D\left\{\frac{1}{P_{11}}+\frac{\alpha_{1} \tilde{\beta}_{1}(\otimes)}{P_{21}}\left\{1-\tilde{\beta}_{1}(\otimes)+F_{1}\right\}\right\}+D \sum_{j=2}^{n}\left\{h_{j}\left(\prod_{p=1}^{j-1} F_{p}\right)^{2}\left\{\frac{1}{P_{1 j}}+\frac{\alpha_{j} \tilde{\beta}_{j}(\otimes)}{P_{2 j}}\left\{1-\tilde{\beta}_{j}(\otimes)+F_{j}\right\}\right\}\right\}+h_{n} F_{n}^{2}\left(\prod_{p=1}^{n-1} F_{p}\right)^{2}}\right]^{\frac{1}{2}}$

After calculating $Q_{1}^{*}$, the optimal production quantities of next stages can be obtained as $Q_{j}^{*}=Q_{1}^{*} \prod_{p=1}^{j-1} F_{p}, \forall j=2,3, \ldots, n$. Moreover, in order to reach the upper and lower limits for optimal objective function, the following mathematical models are constructed.

$$
\min _{\gamma_{j}} \underline{T P U^{M}}(\otimes)=\max _{Q_{1}} T \tilde{P} U^{M}(\otimes) .
$$

subject to.

$$
\begin{gathered}
\tilde{\beta}_{j}(\otimes)=\gamma_{j} \bar{\beta}_{j}+\left(1-\gamma_{j}\right) \underline{\beta}_{j} . \\
0 \leq \gamma_{j} \leq 1 . \\
\max _{\gamma_{j}} \overline{T P U}^{M}(\otimes)=\max _{Q_{1}} T \tilde{P} U^{M}(\otimes) .
\end{gathered}
$$

subject to.

$$
\tilde{\beta}_{j}(\otimes)=\gamma_{j} \bar{\beta}_{j}+\left(1-\gamma_{j}\right) \underline{\beta}_{j} .
$$

ere $\underline{T P U^{M}}(\otimes)$. and $\overline{T P U}^{M}(\otimes)$. represents the lower and upper limits of the objective function (total profit per unit time) as grey number. As mentioned earlier, the aim of grey programming is to recognize the lower and upper limits of the objective function, $T P U^{M}$ in our model, caused by grey input parameters. Note that the first model is a minimax problem (can be solved via conventional minimax commands in Matlab) while the second one is a 
maximization problem with two variables $Q_{1}$ and $\gamma_{j}$ (can be simply solved by nonlinear optimization commands in Matlab). A flowchart from initial stages in order to obtain the optimum solutions has been given in Figure 4 .

\section{Figure $4<<$}

\section{Examples and Analysis}

In order to investigate the performance of the suggested models, two numerical examples are discussed, with one and three stages. Table 3shows the characteristics of these numerical examples. Then, we perform an analysis of sensitivity by changing the value of input parameters, in order to assess the outputs under various inputs.

\section{Table $3<<$}

It is assumed that the whitened value of defective rates is the middle point of upper and lower limits. We first investigate the feasibility conditions for two examples. To this end, we should evaluate three conditions: (i) $P_{1}>D$, (ii) $P_{2}>D$ and (iii) $\beta(\otimes)$ for single stage example. The first two conditions are deterministic while the third one is a grey one. Using the data of the first example, we have $P_{1}=3000>1000=D$, (ii) $P_{2}=4500>1000=D$. On the other hand, the right-hand equation of third condition is $1-1000 / 3000=0.67$. As can be seen, both upper and lower limits of defective rate $\beta$ are less than 0.67 , which ensure feasibility of the first example. We should check out three conditions: (i) $P_{1 j}>D$, (ii) $P_{2 j}>D$ and (iii) $\beta_{j}(\otimes)$ for second example. By doing so, we can simply find that all of the conditions are satisfied for both examples. The first two conditions are satisfied since $P_{11}=1500>800=D$, $P_{21}=3500>800=D, \quad P_{12}=2500>1200=D, \quad P_{22}=3000>1200=D$, 
$P_{13}=2000>500=D$, and $P_{23}=4000>500=D$. Obviously, the third condition is also true for the second example since both upper and lower limits of the defective rate are much less than the production rate in all three stages.

Utilizing the characteristics of the first example, the whitened values of optimal production quantity are obtained by Eq. 21 as 307.2182, and then the total profit per unit time is calculated as 381802.5 Moreover, the whitened production period, rework period and depletion period are attained $0.1024,0.0074$ and 0.1938 respectively. To obtain the possible upper and lower limits for optimal total profit per unit, Eq.s 22 and 23 are calculated for this example. The obtained results are $\underline{T P U}(\otimes)$ and $\overline{T P U}(\otimes)$. Moreover, the whitened values of optimal production quantity of the first stage, for the second example, are obtained by Eq. 42 as 324.0478, and then the production quantities of second and third stages are obtained as 317.5668 and 309.9452. Moreover, the total profit per unit time is calculated as 82385.93 with lower and upper limits 789754.58 and 865741.89 .

We are going to evaluate the relation between the optimal solution and the input grey parameters. In real world, the changes in parameters of the model are inevitable and the parameters fluctuate. Moreover, changes in the parameters may have a significant impact on the values of decision variables and the objective function. In this research, we study the impact of defective rates as grey numbers in the problem on the optimal total profit per unit time. Table 4 presents the results, for the first example, and Figures 5-7 depicts the outputs variations. According to the results obtained, the defective rate has the negative impact on the optimal production, rework and depletion periods. In addition, the production quantities and total profit decrease when the defective rate of process increases. This is a reasonable behavior in manufacturing environments.

\section{Table $4 \ll$}




\section{$>>$ Figure $5<$}

$>>$ Figure $6<$

$>$ Figure $7<<$

These results are also true for the second example. Table 5-7 present the impact of grey defective rates on the optimal solution of second example. Moreover, Figure 8 shows total profit per unit time, under variation of grey defective rates. As an observation, the production quantities at a special stage shows very smooth change when the defective rate(s) of next stages change. For example, when defective rate of third stage increases, the production quantities at first stage remain unchanged (very smooth change).

\section{$>>$ Table $5<<$ \\ Table $6<<$ \\ Table $7<<$}

\section{$>$ Figure $8<$}

\section{Implications and Conclusions}

From practical point of view, this is not necessarily true that all of produced items are of perfect quality every time, and the production processes are not necessarily of perfect quality. Consequently, the production of defective items is inevitable even in high quality and advanced manufacturing units. Usually, a certain fraction of the items is defective which is due to poor quality of the production process or raw materials. From practical point of view, the proposed model in this paper tried to address some more realistic conditions which are usually happened in real-world production systems. Moreover, in a multi-stage production system, products 
are transferred from one stage to the next stage, and every stage may produce a fraction of defective products. A production stage is affected by a number of inevitable undesirable factors, which make it rarely possible for a production machine/production system to produce perfect quality items every time. In fact, in some defective production systems, rework is usually used for imperfect items at every stage. The perfect items, in the proposed model, go to the next stage and finally become finished product at the final stage, and then go under consumption. To address the practical circumstances, the proposed model considers that a fraction of imperfect items is of unacceptable quality and should be disposed as scrap at each stage. The decision of on the quality of a produced item is made by a quality control process in manufacturing companies.

This paper proposed single and multi-stages production-inventory systems with defective manufacturing process, possible rework and scrapped items. The feasibility conditions are extracted for both models to avoid shortage. It is also assumed that the defective rate are uncertain parameters. The grey systems theory, as a mathematical tool to address the uncertain information, is utilized to model the random defective rate via a grey programming in both models. From theoretical point of view, this is a new kind of mathematical programming problems with its own challenges and complications. Since the proposed production-inventory problems are unconstrained nonlinear optimization problem, we employ the grey nonlinear programming principles to address the complexities occurred in the solving process. The total profit per unit time is derived from both models, in terms of whitened random defective rate, and then the optimal production quantities are calculated for each model separately. Two numerical examples are presented and studied to assess the impact of grey parameters on optimal solutions. The grey programming generates feasible ranges of decision variables and objective functions using the interpretation of the grey solutions and grey input parameters, it has lower computational 
efforts compared with the existing methods, and then is applicable to practical problems, and does not require distribution information (like probability based approaches) or membership function (like fuzzy based approaches) for input parameters, since interval numbers are acceptable for the input parameters.

As an opportunity for future research, it can be considered to incorporate other uncertain parameters into proposed models like demand rate or reworkable item rate, to reach a more practical problem, and address it via grey programming. Moreover, it is interesting to employ other approaches like stochastic programming to handle the uncertainties in our models.

\section{REFERENCES}

1. Lin, Y., Chen, M.Y., and Liu, S. "Theory of grey systems: capturing uncertainties of grey information". Kybernetes. (2004).

2. Aghajani, M., Keramati, A., Moghadam, R.T. and Mirjavadi, S.S. "A mathematical programming model for cellular manufacturing system controlled by kanban with rework consideration". The International Journal of Advanced Manufacturing Technology, 83(5-8), pp.1377-1394 (2016).

3. Peng, C.Y., and Khasawneh, M.T. "A Markovian approach to determining optimum process means with inspection sampling plan in serial production systems". The International Journal of Advanced Manufacturing Technology, 72(9), pp.1299-1323 (2014).

4. Salameh, M.K., and Jaber, M.Y. "Economic production quantity model for items with imperfect quality". International journal of production economics, 64(13), pp.59-64 (2000).

5. Ben-Daya, M., and Rahim, A. "Optimal lot-sizing, quality improvement and inspection errors for multistage production systems". International Journal of Production Research, 41(1), pp.65-79 (2003).

6. Ben-Daya, M., Noman, S.M., and Hariga, M. "Integrated inventory control and inspection policies with deterministic demand". Computers \& operations research, 33(6), pp.1625-1638 (2006).

7. Ojha, D., Sarker, B.R., and Biswas, P. "An optimal batch size for an imperfect production system with quality assurance and rework". International Journal of Production Research, 45(14), pp.3191-3214 (2007). 
8. Sarker, B.R., Jamal, A.M.M., and Mondal, S. "Optimal batch sizing in a multi-stage production system with rework consideration". European Journal of Operational Research, 184(3), pp.915-929 (2008).

9. Biswas, P., and Sarker, B.R. "Optimal batch quantity models for a lean production system with in-cycle rework and scrap". International Journal of Production Research, 46(23), pp.6585-6610 (2008).

10. Wee, H.M., and Widyadana, G.A. "Economic production quantity models for deteriorating items with rework and stochastic preventive maintenance time". International Journal of Production Research, 50(11), pp.2940-2952 (2012).

11. Krishnamoorthi, C., and Panayappan, S. "An EPQ model with imperfect production systems with rework of regular production and sales return". American Journal of Operations Research, 2(2), pp.225-234 (2017).

12. Yoo, S.H., Kim, D., and Park, M.S. "Inventory models for imperfect production and inspection processes with various inspection options under one-time and continuous improvement investment". Computers \& Operations Research, 39(9), pp.2001-2015 (2012).

13. Colledani, M., and Tolio, T. "Integrated analysis of quality and production logistics performance in manufacturing lines". International Journal of Production Research, 49(2), pp.485-518 (2011).

14. Wee, H.M., Wang, W.T., and Yang, P.C. "A production quantity model for imperfect quality items with shortage and screening constraint". International Journal of Production Research, 51(6), pp.1869-1884 (2013).

15. Paul, S.K., Sarker, R., and Essam, D. "A disruption recovery plan in a three-stage production-inventory system". Computers \& Operations Research, 57, pp.6072 (2015).

16. Mahata, G.C. "A production-inventory model with imperfect production process and partial backlogging under learning considerations in fuzzy random environments". Journal of Intelligent Manufacturing, 28(4), pp.883897 (2017).

17. Jaggi, C.K., Cárdenas-Barrón, L.E., Tiwari, S., and Shafi, A. "Two-warehouse inventory model for deteriorating items with imperfect quality under the conditions of permissible delay in payments". Scientia Iranica, 24(1), pp.390412 (2017).

18. Kamali, A., Fatemi Ghomi, S.M.T. and Jolai, F. "Model and optimization of the multi-objective single-buyer multi-vendor integrated inventory problem with multiple quantity discounts". Scientia Iranica, 24(2), pp.856-867 (2017).

19. Nobil, A.H., Afshar Sedigh, A.H., and Cárdenas-Barrón, L.E. "Multi-machine economic production quantity for items with scrapped and rework with 
shortages and allocation decisions". Scientia Iranica, 25(4), pp.2331-2346 (2018).

20. Cheng, Y.L., Wang, W.T., Wei, C.C. and Lee, K.L. "An integrated lot-sizing model for imperfect production with multiple disposals of defective items". Scientia Iranica, 25(2), pp.852-867 (2018).

21. Mokhtari, H. "A joint internal production and external supplier order lot size optimization under defective manufacturing and rework". The International Journal of Advanced Manufacturing Technology, 95(1), pp.1039-1058 (2018).

22. Nobil, A.H., Afshar Sedigh, A.H., Tiwari, S. and Wee, H.M. "An imperfect multiitem single machine production system with shortage, rework, and scrapped considering inspection, dissimilar deficiency levels, and non-zero setup times". Scientia Iranica, 26(1), pp.557-570 (2019).

23. Mokhtari, H., and Asadkhani, J. "Economic order quantity for imperfect quality items under inspection errors, batch replacement and Multiple sales of returned items". Scientia Iranica (2019).

24. Mokhtari, H. "Optimal lot size in a manufacturing system with imperfect raw materials and defective finished products". Scientia Iranica, 26(4), pp.25612578 (2019).

25. Yang, C.T., Huang, C.H. and Ouyang, L.Y. "Optimal production and ordering strategies with defective items and allowable shortage under two-part trade credit". Scientia Iranica, 26(1), pp.503-521 (2019).

26. Beranek, M., and Buscher, U. "Optimal price and quality decisions of a supply chain game considering imperfect quality items and market segmentation". Applied Mathematical Modelling, 91, pp.1227-1244 (2021).

27. Adak, S., and Mahapatra, G.S. "Imperfect and variable production cost in threelayer supply chain system incorporating deterioration and screening effect." Scientia Iranica, (In Press).

28. Cai, Y.P., Huang, G.H., Wang, X., Li, G.C., and Tan, Q. "An inexact programming approach for supporting ecologically sustainable water supply with the consideration of uncertain water demand by ecosystems". Stochastic Environmental Research and Risk Assessment, 25(5), pp.721-735 (2011).

Hadi Mokhtari is currently an Associate Professor of Industrial Engineering at University of Kashan, Iran. His current research interests include the applications of operations research and artificial intelligence techniques to the areas of project scheduling, production scheduling, and supply chain management problems. He also published several papers in international journals such as Computers and Operations Research, International Journal of Production Research, Applied Soft Computing, Journal of Cleaner Production, Neurocomputing, International 
Journal of Advanced Manufacturing Technology, IEEE Transactions on Engineering Management, and Expert Systems with Applications.

Aliakbar Hasani is currently an Associate Professor of Industrial Engineering in Shahrood University of Technology, Iran. His current research interests supply chain management, production planning and scheduling, multi-objective optimization problems, meta-heuristics, quality management and productivity. He also published several papers in international journals such as International Journal of Production Research, Transportation Research Part E, Journal of Cleaner Production, Computers \& Chemical Engineering, Socio-Economic Planning Sciences, Journal of Manufacturing Systems, Resources Policy, and Safety Science.

Saeed Dehnavi-Arani has been graduated in BSc of Industrial Engineering at Tehran University, MSc of Industrial Engineering at Iran University of Science and Technology and PhD of Industrial Engineering at Yazd University at 2010, 2015 and 2019 respectively. His research interests are robot scheduling and routing, cellular manufacturing systems and supply chain management. He also published several papers in international journals such as Computers and Industrial Engineering, Soft Computing, International Journal of Operational Research and International Journal of Industrial Engineering \& Production Research.

\section{Table 1: Nomenclature}

\begin{tabular}{|l|l|}
\hline$j:$ Stages of manufacturing system & $\begin{array}{l}P C^{S}: \text { The total production cost for } \\
\text { single-stage system }\end{array}$ \\
\hline $\begin{array}{l}\beta^{s}(\otimes) \text { : A grey number for defective } \\
\text { rate of the single-stage system }\end{array}$ & $\begin{array}{l}H C^{S}: \text { The total holding cost for } \\
\text { single-stage system }\end{array}$ \\
\hline $\begin{array}{l}P^{S}: \text { The production rate in single- } \\
\text { stage system }\end{array}$ & $\begin{array}{l}S_{I}{ }^{S}: \text { The area below the first period } \\
\text { (production) in a single-stage system }\end{array}$ \\
\hline $\begin{array}{l}P_{2}^{S}: \text { The rework process rate in } \\
\text { single-stage system }\end{array}$ & $\begin{array}{l}S_{I I}{ }^{S}: \text { The area below the second } \\
\text { period (rework) in a single-stage } \\
\text { system }\end{array}$ \\
\hline
\end{tabular}




\begin{tabular}{|c|c|}
\hline $\begin{array}{l}\alpha: \text { The rate of reworkable items rate } \\
\text { in single-stage system }\end{array}$ & $\begin{array}{l}S_{I I I}^{S}: \text { The area below the third period } \\
\text { (depletion) in a single-stage system }\end{array}$ \\
\hline$r^{s}:$ The cost of rework item & $\begin{array}{l}W C^{S} \text { : The total cost of screening in a } \\
\text { single-stage system }\end{array}$ \\
\hline $\begin{array}{l}D^{S}: \text { The demand toward single- } \\
\text { stage system }\end{array}$ & $\begin{array}{l}R C^{S}: \text { The total cost of rework in a } \\
\text { single-stage system }\end{array}$ \\
\hline $\begin{array}{l}v^{s}: \text { The sale price of perfect item in } \\
\text { single-stage system }\end{array}$ & $\begin{array}{l}T C^{S}: \text { The total cost for a single-stage } \\
\text { system }\end{array}$ \\
\hline $\begin{array}{l}s^{s}: \text { The sale price of scrapped item } \\
\text { in single-stage system }\end{array}$ & $\begin{array}{l}T \tilde{P}^{s}(\otimes) \text { : The whitened value of total } \\
\text { profit in a single-stage system }\end{array}$ \\
\hline $\begin{array}{l}C^{S}: \text { The production unit cost in } \\
\text { single-stage system }\end{array}$ & $\begin{array}{l}T \tilde{P} U^{s}(\otimes) \text { The whitened value of total } \\
\text { profit per unit time in a single-stage } \\
\text { system }\end{array}$ \\
\hline $\begin{array}{l}S C^{S}: \text { The total setup cost in single- } \\
\text { stage system equal to } A^{S}\end{array}$ & $\begin{array}{l}\tilde{T}^{s}(\otimes) \text { The whitened inventory cycle } \\
\text { time }\end{array}$ \\
\hline $\begin{array}{l}h^{S} \text { : The holding unit cost in single- } \\
\text { stage system }\end{array}$ & $\begin{array}{l}t_{P}^{S}: \text { The production interval in the } \\
\text { single-stage system }\end{array}$ \\
\hline $\begin{array}{l}d^{s} \text { : The screening unit cost in single- } \\
\text { stage system }\end{array}$ & $\begin{array}{l}t^{S}: \text { The rework interval in the } \\
\text { single-stage system }\end{array}$ \\
\hline $\begin{array}{l}P_{1 j}: \text { The production rate for stage } \\
j \text { th in multi-stage system }\end{array}$ & $\begin{array}{l}t_{D}^{S}: \text { The depletion interval in the } \\
\text { single-stage system }\end{array}$ \\
\hline $\begin{array}{l}P_{2 j}: \text { The rework process rate for } \\
\text { stage } j \text { th in multi-stage system }\end{array}$ & $\begin{array}{l}Q^{S^{*}}: \text { The optimal quantity in a } \\
\text { single-stage system }\end{array}$ \\
\hline $\begin{array}{l}\beta_{j}(\otimes) \text { : A grey number for defective } \\
\text { rate for stage } j \text { th in multi-stage } \\
\text { system }\end{array}$ & $\begin{array}{l}T P^{M}: \text { The total profit in a multi-stage } \\
\text { system }\end{array}$ \\
\hline $\begin{array}{l}\alpha_{j}: \text { The rate of reworkable items for } \\
\text { stage } j \text { th in multi-stage system }\end{array}$ & $\begin{array}{l}T C^{M}: \text { The total cost in a multi-stage } \\
\text { system }\end{array}$ \\
\hline $\begin{array}{l}t_{P j}^{S}: \text { The production interval for } \\
\text { stage } j \text { th in multi-stage system }\end{array}$ & $\begin{array}{l}T R^{M}: \text { The total revenue in a multi- } \\
\text { stage system }\end{array}$ \\
\hline $\begin{array}{l}\alpha_{j}: \text { The rate of reworkable items for } \\
\text { stage } j \text { th in multi-stage system }\end{array}$ & $\begin{array}{l}P C^{M}: \text { The total production cost for } \\
\text { multi-stage system }\end{array}$ \\
\hline $\begin{array}{l}t_{D j}^{S}: \text { The depletion interval for stage } \\
j \text { th in multi-stage system }\end{array}$ & $\begin{array}{l}H C^{M}: . \text { The total holding cost for } \\
\text { multi-stage system }\end{array}$ \\
\hline $\begin{array}{l}D: \text { The demand toward multi-stage } \\
\text { system }\end{array}$ & $\begin{array}{l}S_{l j}: \text { The area below the first period } \\
\text { (production) for stage } j \text { th in multi- } \\
\text { stage system }\end{array}$ \\
\hline $\begin{array}{l}v: \text { The sale price of perfect item in } \\
\text { multi-stage system }\end{array}$ & $\begin{array}{l}S_{I I j}: \text { The area below the second } \\
\text { period (rework) for stage } j \text { th in } \\
\text { multi-stage system }\end{array}$ \\
\hline
\end{tabular}




\begin{tabular}{|c|c|}
\hline $\begin{array}{l}s_{j}: \text { The sale price of scrapped item } \\
\text { for stage } j \text { th in multi-stage system }\end{array}$ & $\begin{array}{l}S_{I I I j}: \text { The area below the third period } \\
\text { (depletion) for stage } j \text { th in multi- } \\
\text { stage system }\end{array}$ \\
\hline $\begin{array}{l}C_{j}: \text { The production unit cost for } \\
\text { stage } j \text { th in multi-stage system }\end{array}$ & $\begin{array}{l}W C^{M}: \text { The total cost of screening } \\
\text { multi-stage system }\end{array}$ \\
\hline $\begin{array}{l}S C^{S} \text { :The total setup cost in multi- } \\
\text { stage system }\end{array}$ & $\begin{array}{l}R C^{S}: \text { The total cost of rework in a } \\
\text { single-stage system }\end{array}$ \\
\hline $\begin{array}{l}A_{j}: \text { The setup cost for stage } j \text { th in } \\
\text { multi-stage system }\end{array}$ & $\begin{array}{l}T C^{S}: \text { The total cost for a single-stage } \\
\text { system }\end{array}$ \\
\hline $\begin{array}{l}h_{j}: \text { The holding unit cost for stage } j \\
\text { th in multi-stage system }\end{array}$ & $\begin{array}{l}T \tilde{P}^{M}(\otimes): \text { The whitened value of total } \\
\text { profit in multi-stage system }\end{array}$ \\
\hline $\begin{array}{l}d_{j}: \text { The screening unit cost for stage } \\
j \text { th in multi-stage system }\end{array}$ & $\begin{array}{l}T \tilde{P} U^{M}(\otimes) \text { : The whit } \\
\text { total profit per unit } \\
\text { stage system }\end{array}$ \\
\hline $\begin{array}{l}r_{j}: \text { The cost of rework item for stage } \\
j \text { th in multi-stage system }\end{array}$ & $\begin{array}{l}\tilde{T}^{M}(\otimes): \text { The whitened inventory } \\
\text { cycle time }\end{array}$ \\
\hline $\begin{array}{l}Q_{j}: \text { The production quantity for } \\
\text { stage } j \text { th in multi-stage system }\end{array}$ & $\begin{array}{l}t_{P j}: \text { The production interval for stage } \\
j \text { th in multi-stage system }\end{array}$ \\
\hline $\begin{array}{l}I_{\text {max }}^{S_{\text {max }}} \text { The maximum inventory level } \\
\text { for single-stage system }\end{array}$ & $\begin{array}{l}t_{R j}: \text { The rework interval for stage } j \text { th } \\
\text { in multi-stage system }\end{array}$ \\
\hline $\begin{array}{l}\mathrm{Q}^{S}: \text { The production quantity in } \\
\text { single-stage system }\end{array}$ & $\begin{array}{l}t_{D j}: \text { The depletion interval for stage } \\
j \text { th in multi-stage system }\end{array}$ \\
\hline $\begin{array}{l}T P^{S}: \text { The total profit in a single-stage } \\
\text { system }\end{array}$ & $\begin{array}{l}Q_{j}^{*}: \text { The optimal quantity for stage } \\
j \text { th in multi-stage system }\end{array}$ \\
\hline $\begin{array}{l}T C^{S}: \text { The total cost in a single-stage } \\
\text { system }\end{array}$ & $\begin{array}{l}I_{1 j}: \text { The inventory level at the start of } \\
\text { rework period for stage } j \text { th in multi- } \\
\text { stage system }\end{array}$ \\
\hline $\begin{array}{l}T R^{S} \text { : The total revenue in a single- } \\
\text { stage system }\end{array}$ & $\begin{array}{l}I_{2 j}: \text { The inventory level at the end of } \\
\text { rework period for stage } j \text { th in multi- } \\
\text { stage system }\end{array}$ \\
\hline
\end{tabular}

Table 2: The properties of reviewed papers in literature

\begin{tabular}{|l|c|c|c|c|c|}
\hline \multirow{2}{*}{ Paper } & \multirow{2}{*}{ EOQ/EPQ } & \multicolumn{3}{|c|}{ Environment } & $\begin{array}{c}\text { Kind of } \\
\text { uncertainty for } \\
\text { percentage of } \\
\text { defected items }\end{array}$ \\
\cline { 3 - 6 } & Single- & $\begin{array}{c}\text { Multi- } \\
\text { stage }\end{array}$ & $\begin{array}{c}\text { Supply- } \\
\text { shain }\end{array}$ & $\begin{array}{c}\text { probability } \\
\text { density } \\
\text { function }\end{array}$ \\
\hline $\begin{array}{l}\text { Salameh and Jaber } \\
(2000)\end{array}$ & EOQ & $*$ & & & \\
\hline
\end{tabular}




\begin{tabular}{|c|c|c|c|c|c|}
\hline $\begin{array}{l}\text { Ben-Daya and Rahim } \\
\text { (2003) }\end{array}$ & EPQ & & $*$ & & constant rate \\
\hline Ben-Daya et al. (2006) & EOQ & * & & & $\begin{array}{c}\text { beta } \\
\text { distribution }\end{array}$ \\
\hline Ojha et al. (2007) & EPQ & $*$ & & & constant rate \\
\hline Sarker et al. (2007) & EPQ & & $*$ & & constant rate \\
\hline Sarker (2008) & EOQ & $*$ & & & constant rate \\
\hline $\begin{array}{l}\text { Wee and Widyadana } \\
\text { (2012) }\end{array}$ & EPQ & * & & & constant rate \\
\hline $\begin{array}{l}\text { Krishnamoorthi and } \\
\text { Panayappan (2012) }\end{array}$ & EPQ & * & & & constant rate \\
\hline Yoo, et al. (2012) & EPQ & & $*$ & & constant rate \\
\hline $\begin{array}{l}\text { Colledani and Tolio } \\
\text { (2011) }\end{array}$ & EPQ & & * & & constant rate \\
\hline Wee et al. (2013) & EOQ & $*$ & & & $\begin{array}{c}\text { probability } \\
\text { density } \\
\text { function }\end{array}$ \\
\hline Paul et al. (2015) & EPQ & & $*$ & & constant rate \\
\hline Mahata (2017) & EPQ & $*$ & & & Fuzzy number \\
\hline Jaggi et al. (2017) & EPQ & & & $*$ & $\begin{array}{c}\text { probability } \\
\text { density } \\
\text { function }\end{array}$ \\
\hline Kamali et al. (2017) & EPQ & & & $*$ & constant rate \\
\hline Nobil et al. (2018) & EPQ & & $*$ & & constant rate \\
\hline Cheng et al. (2018) & EOQ & & * & & $\begin{array}{c}\text { probability } \\
\text { density } \\
\text { function }\end{array}$ \\
\hline Mokhtari (2018) & EPQ & $*$ & & & $\begin{array}{c}\text { probability } \\
\text { density } \\
\text { function }\end{array}$ \\
\hline Nobil, et al. (2019) & EPQ & $*$ & & & constant rate \\
\hline $\begin{array}{l}\text { Mokhtari and } \\
\text { Asadkhani (2019) }\end{array}$ & EOQ & $*$ & & & $\begin{array}{c}\text { probability } \\
\text { density } \\
\text { function }\end{array}$ \\
\hline Mokhtari (2019) & EPQ & & $*$ & & constant rate \\
\hline Yang, et al. (2019) & EOQ & $*$ & & & constant rate \\
\hline $\begin{array}{l}\text { Beranek and Buscher } \\
(2020)\end{array}$ & EPQ & $*$ & & & constant rate \\
\hline
\end{tabular}




\begin{tabular}{|l|l|l|l|l|l|}
\hline Mahapatra (2020) & EPQ & & & $*$ & constant rate \\
\hline This paper & EPQ & $*$ & $*$ & & grey number \\
\hline
\end{tabular}

Table 3: The characteristics of numerical examples

\begin{tabular}{|l|c|c|c|c|}
\hline \multirow{2}{*}{ parameters } & \multicolumn{3}{|c|}{ Multi stage } & \multirow{2}{*}{ Single stage } \\
\cline { 2 - 4 } & $j=1$ & $j=2$ & $j=3$ & \\
\hline Production rate $P_{1 j}$ & 1500 & 2500 & 2000 & 3000 \\
\hline Rework rate $P_{2 j}$ & 3500 & 3000 & 4000 & 4500 \\
\hline $\begin{array}{l}\text { Rate of reworkable items } \\
\alpha_{j}\end{array}$ & 0.80 & 0.70 & 0.85 & 0.90 \\
\hline Setup cost $A_{j}$ & 100 & 50 & 200 & 150 \\
\hline Holding cost $h_{j}$ & 10 & 8 & 4 & 12 \\
\hline Production cost $C_{j}$ & 50 & 30 & 80 & 40 \\
\hline Screening cost $d_{j}$ & 30 & 35 & 20 & 25 \\
\hline Reworking cost $r_{j}$ & 10 & 5 & 8 & 12 \\
\hline Scrapped item unit price $s_{j}$ & 50 & 25 & 75 & 50 \\
\hline Perfect product unit price $v$ & 500 & 500 & 500 & 450 \\
\hline Demand rate $D$ & 800 & 800 & 800 & 1000 \\
\hline $\begin{array}{l}\text { Defective rate } \beta_{j} \text { (grey } \\
\text { number) }\end{array}$ & {$[0.10,0.15]$} & {$[0.08,0.12]$} & {$[0.04,0.08]$} & {$[0.10,0.14]$} \\
\hline
\end{tabular}

Table 4: The impact of grey defective rate on optimal solution (first example)

\begin{tabular}{|c|c|c|c|c|c|}
\hline $\begin{array}{c}\text { Variation on } \\
\text { whitened } \beta\end{array}$ & $t_{P}$ & $t_{R}$ & $t_{D}$ & $Q^{*}$ & $T P U$ \\
\hline$-50 \%$ & 0.1074 & 0.0039 & 0.2090 & 322.1544 & 382509.47 \\
\hline$-40 \%$ & 0.1064 & 0.0046 & 0.2060 & 319.2700 & 382368.63 \\
\hline$-30 \%$ & 0.1054 & 0.0053 & 0.2029 & 316.3267 & 382227.54 \\
\hline$-20 \%$ & 0.1044 & 0.0060 & 0.1999 & 313.3321 & 382086.18 \\
\hline$-10 \%$ & 0.1034 & 0.0067 & 0.1968 & 310.2936 & 381944.51 \\
\hline $0 \%$ & 0.1024 & 0.0074 & 0.1938 & 307.2182 & 381802.51 \\
\hline$+10 \%$ & 0.1014 & 0.0080 & 0.1907 & 304.1124 & 381660.14 \\
\hline$+20 \%$ & 0.1003 & 0.0087 & 0.1877 & 300.9827 & 381517.39 \\
\hline$+30 \%$ & 0.0993 & 0.0093 & 0.1846 & 297.8350 & 381374.22 \\
\hline$+40 \%$ & 0.0982 & 0.009 & 0.1816 & 294.6749 & 381230.62 \\
\hline
\end{tabular}




\begin{tabular}{|c|c|c|c|c|c|}
\hline $\begin{array}{l}\text { Variation on } \\
\text { whitened } \beta\end{array}$ & $t_{P}$ & $t_{R}$ & $t_{D}$ & $Q^{*}$ & $T P U$ \\
\hline$+50 \%$ & 0.0972 & 0.0105 & 0.1786 & 291.5077 & 381086.57 \\
\hline
\end{tabular}

Table 5: The impact of first stage grey defective rate on optimal solution (second example)

\begin{tabular}{|c|c|c|c|c|c|}
\hline $\begin{array}{c}\text { Variation on } \\
\text { whitened } \beta_{1}\end{array}$ & $Q_{1}^{*}$ & $Q_{2}^{*}$ & $Q_{3}^{*}$ & $T$ & $T P U$ \\
\hline$-50 \%$ & 324.0484 & 319.9978 & 310.3979 & 0.8998 & 83415.31 \\
\hline$-40 \%$ & 324.0482 & 319.1875 & 309.6118 & 0.8990 & 83210.07 \\
\hline$-30 \%$ & 324.0480 & 318.3771 & 308.8258 & 0.8982 & 83004.52 \\
\hline$-20 \%$ & 324.0478 & 317.5668 & 308.0398 & 0.8974 & 82798.64 \\
\hline$-10 \%$ & 324.0475 & 316.7565 & 307.2538 & 0.8966 & 82592.45 \\
\hline $0 \%$ & 324.0473 & 315.9461 & 306.4678 & 0.8958 & 385.93 \\
\hline$+10 \%$ & 324.0471 & 315.1358 & 305.6818 & 0.8950 & 82179.09 \\
\hline$+20 \%$ & 324.0469 & 314.3255 & 304.8957 & 0.8942 & 81972.38 \\
\hline$+30 \%$ & 324.0467 & 313.5152 & 304.1097 & 0.8934 & 81764.43 \\
\hline$+40 \%$ & 324.0465 & 312.7049 & 303.3237 & 0.8926 & 81556.61 \\
\hline$+50 \%$ & 324.0463 & 311.8946 & 302.5377 & 0.8918 & 81348.46 \\
\hline
\end{tabular}

Table 6: The impact of second stage grey defective rate on optimal solution (second example)

\begin{tabular}{|c|c|c|c|c|c|}
\hline $\begin{array}{c}\text { Variation on } \\
\text { whitened } \beta_{2}\end{array}$ & $Q_{1}^{*}$ & $Q_{2}^{*}$ & $Q_{3}^{*}$ & $T$ & $T P U$ \\
\hline$-50 \%$ & 324.0473 & 315.9461 & 311.2069 & 0.9004 & 83974.49 \\
\hline$-40 \%$ & 324.0473 & 315.9461 & 310.2591 & 0.8995 & 83658.04 \\
\hline$-30 \%$ & 324.0473 & 315.9461 & 309.3113 & 0.8985 & 83340.96 \\
\hline$-20 \%$ & 324.0473 & 315.9461 & 308.3634 & 0.8976 & 83023.25 \\
\hline$-10 \%$ & 324.0473 & 315.9461 & 307.4156 & 0.8967 & 82704.91 \\
\hline $0 \%$ & 324.0473 & 315.9461 & 306.4678 & 0.8958 & 82385.93 \\
\hline$+10 \%$ & 324.0473 & 315.9461 & 305.5199 & 0.8949 & 82066.32 \\
\hline$+20 \%$ & 324.0473 & 315.9461 & 304.5721 & 0.8940 & 746.06 \\
\hline$+30 \%$ & 324.0473 & 315.9461 & 303.6242 & 0.8930 & 425.16 \\
\hline$+40 \%$ & 324.0473 & 315.9461 & 302.6764 & 0.8921 & 81103.61 \\
\hline$+50 \%$ & 324.0473 & 315.9461 & 301.7285 & 0.8912 & 80781.42 \\
\hline
\end{tabular}


Table 7: The impact of third stage grey defective rate on optimal solution (second example)

\begin{tabular}{|c|c|c|c|c|c|}
\hline $\begin{array}{c}\text { Variation on } \\
\text { whitened } \beta_{3}\end{array}$ & $Q_{1}^{*}$ & $Q_{2}^{*}$ & $Q_{3}^{*}$ & $T$ & $T P U$ \\
\hline$-50 \%$ & 324.0473 & 315.9461 & 306.4678 & 0.8955 & 83131.53 \\
\hline$-40 \%$ & 324.0473 & 315.9461 & 306.4678 & 0.8956 & 82982.37 \\
\hline$-30 \%$ & 324.0473 & 315.9461 & 306.4678 & 0.8956 & 82833.23 \\
\hline$-20 \%$ & 324.0473 & 315.9461 & 306.4678 & 0.8957 & 82684.11 \\
\hline$-10 \%$ & 324.0473 & 315.9461 & 306.4678 & 0.8957 & 82535.01 \\
\hline $0 \%$ & 324.0473 & 315.9461 & 306.4678 & 0.8958 & 82385.93 \\
\hline$+10 \%$ & 324.0473 & 315.9461 & 306.4678 & 0.8959 & 82236.87 \\
\hline$+20 \%$ & 324.0473 & 315.9461 & 306.4678 & 0.8959 & 82087.83 \\
\hline$+30 \%$ & 324.0473 & 315.9461 & 306.4678 & 0.8960 & 81938.80 \\
\hline$+40 \%$ & 324.0473 & 315.9461 & 306.4678 & 0.8960 & 81789.79 \\
\hline$+50 \%$ & 324.0473 & 315.9461 & 306.4678 & 0.8960 & 81640.80 \\
\hline
\end{tabular}

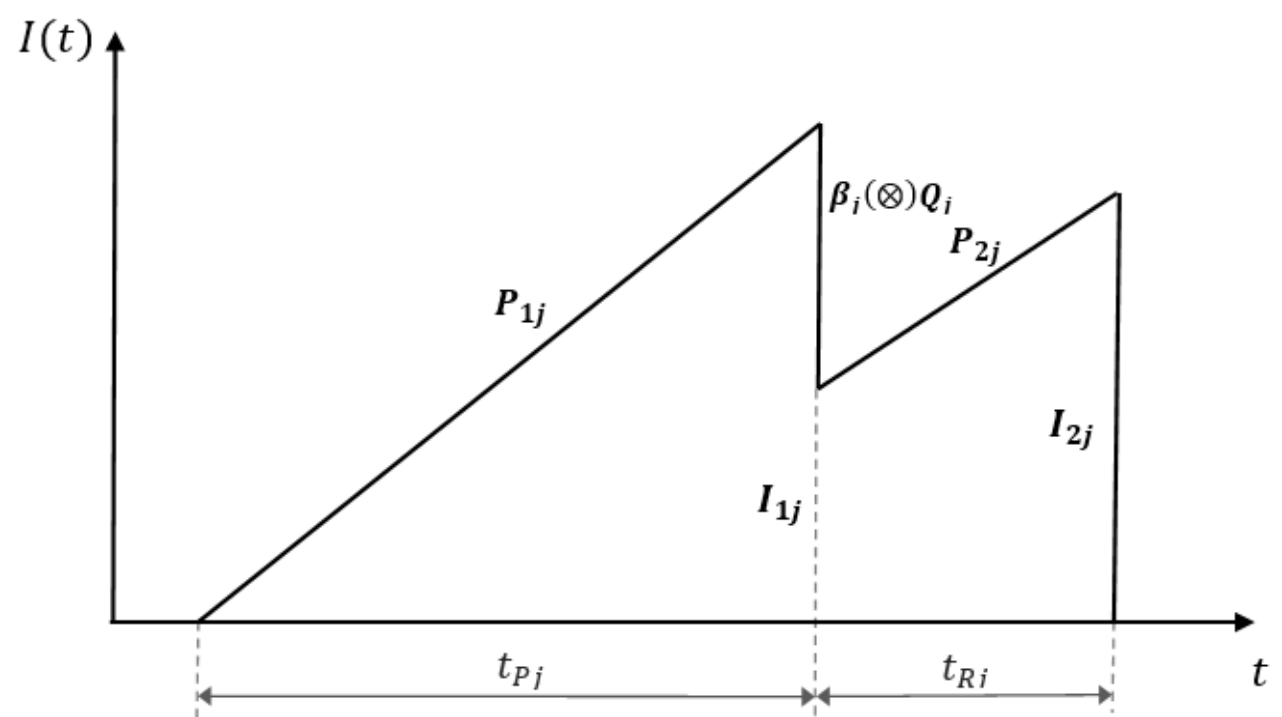

Figure 1: The inventory level for $j$ th $(j=1,2, \ldots, n-1)$ stage of multi stage manufacturing system 


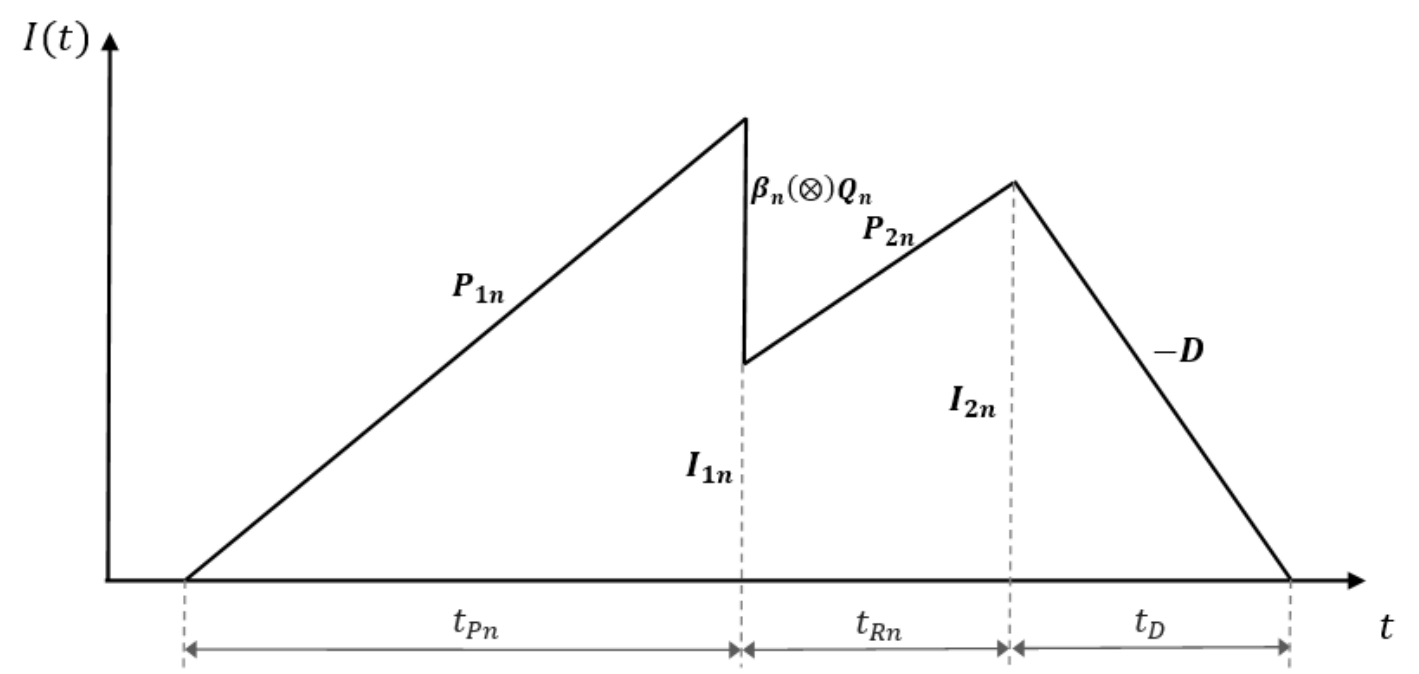

Figure 2: The inventory level for $n$th stage (final stage) of multi stage manufacturing system 


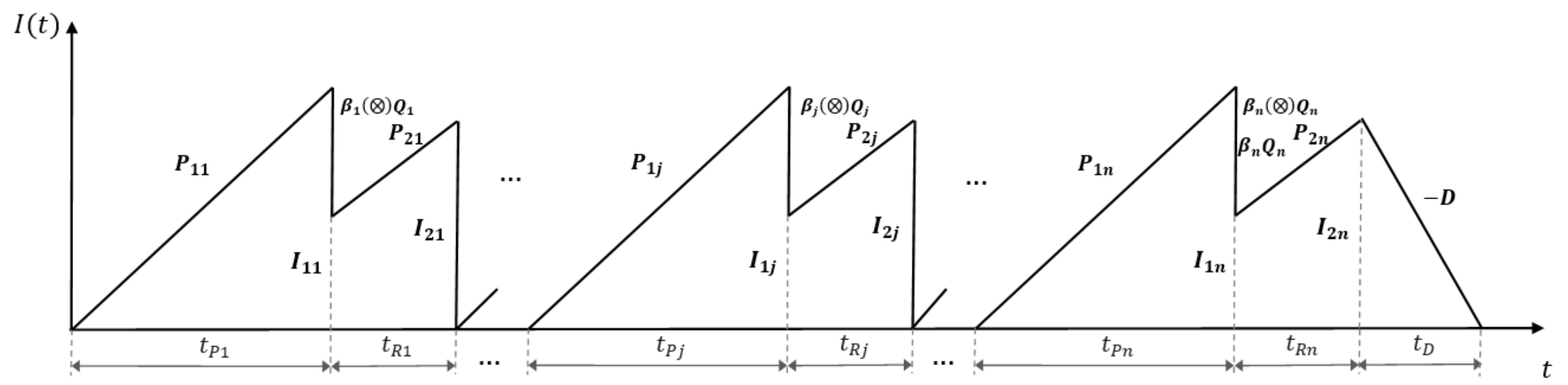

Figure 3: The inventory level for a multi stage manufacturing system 

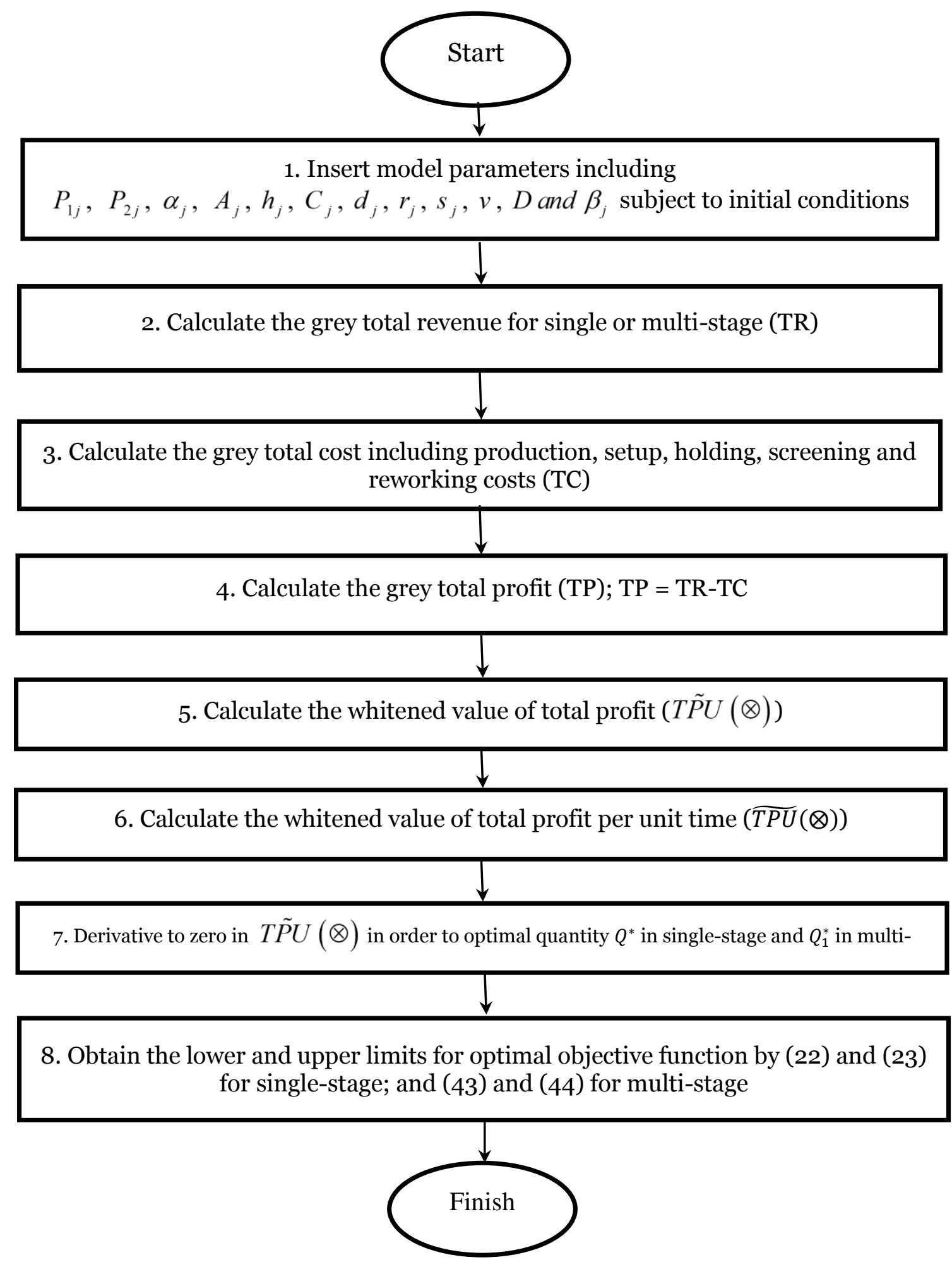

Figure 4 . The flowchart of proposed approach 


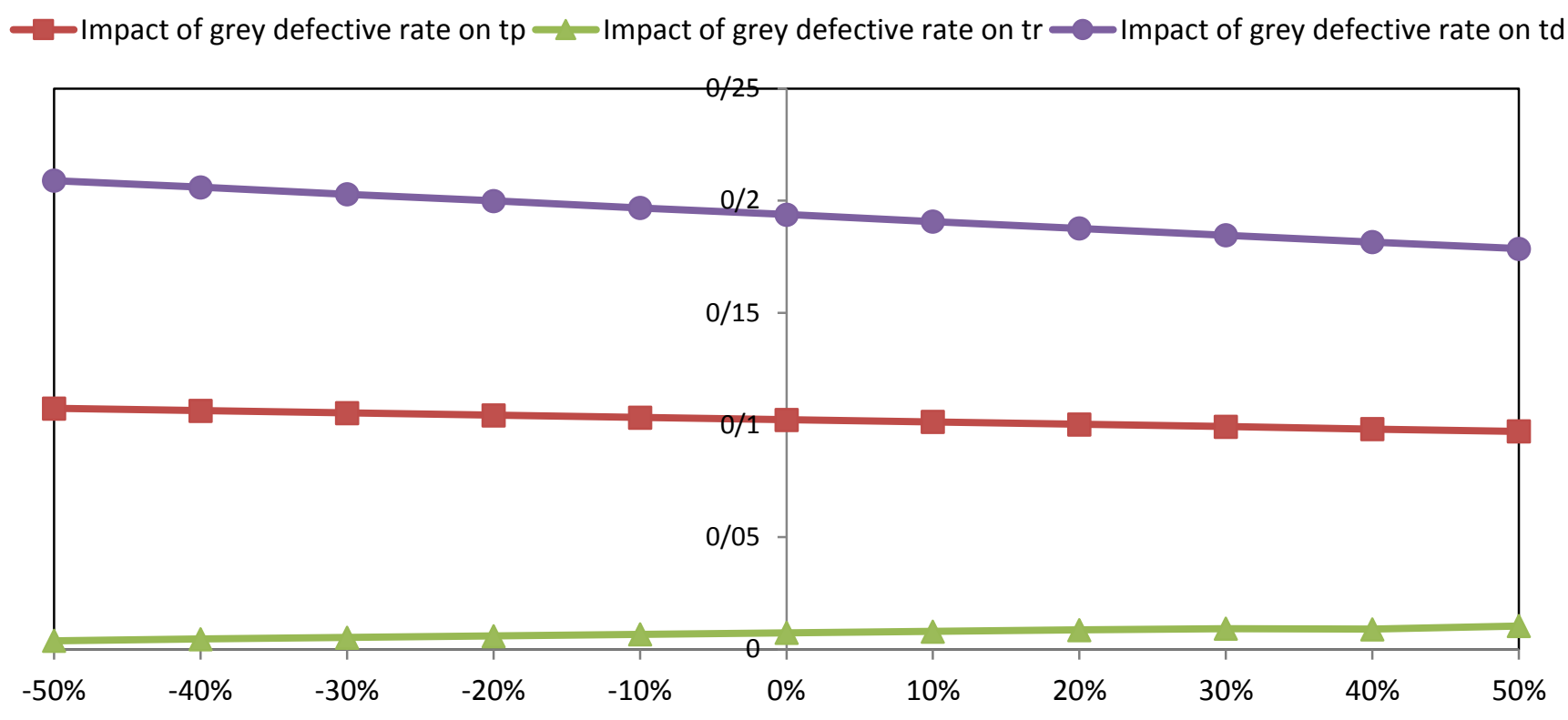

Figure 5: The impact of grey defective rate on production rework and depletion periods (first example)

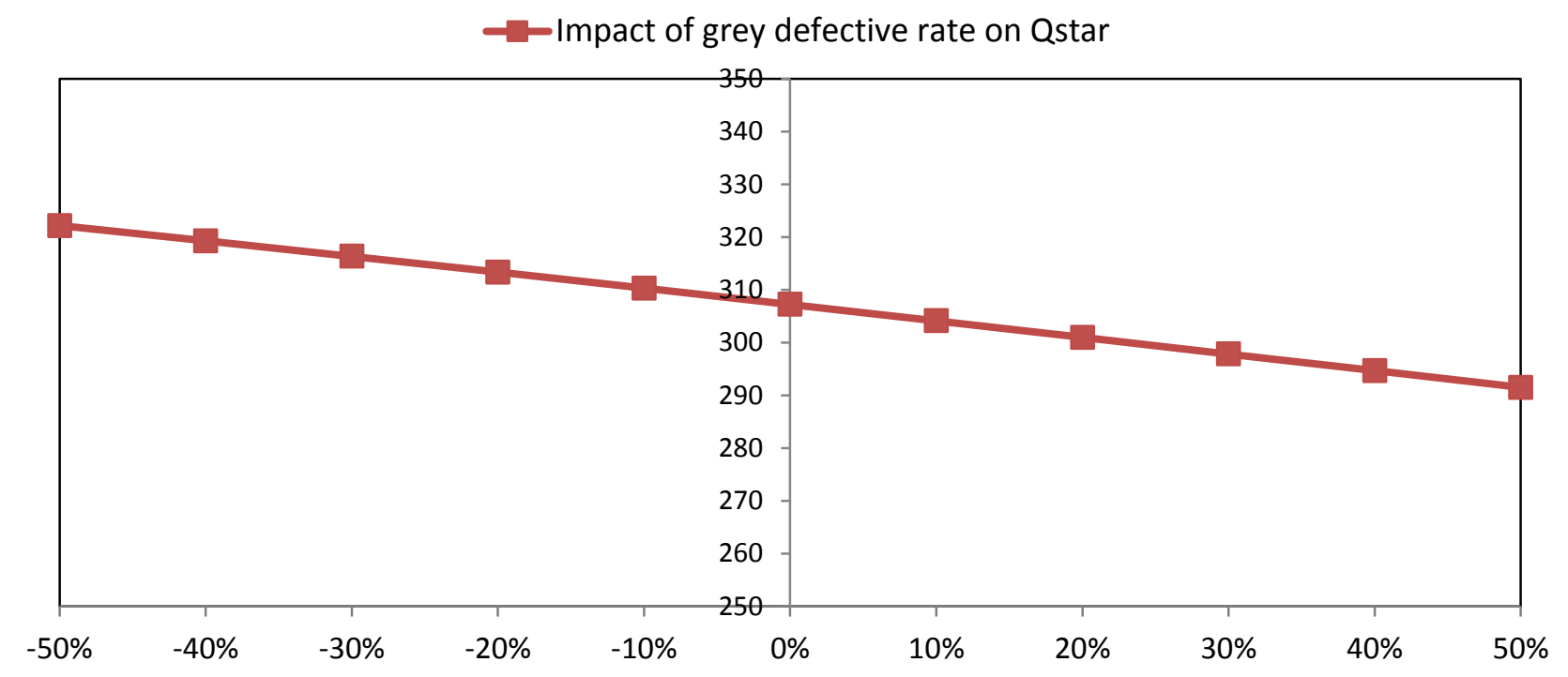

Figure 6: The impact of grey defective rate on optimal production quantity (first example) 
-Impact of grey defective rate on TPU

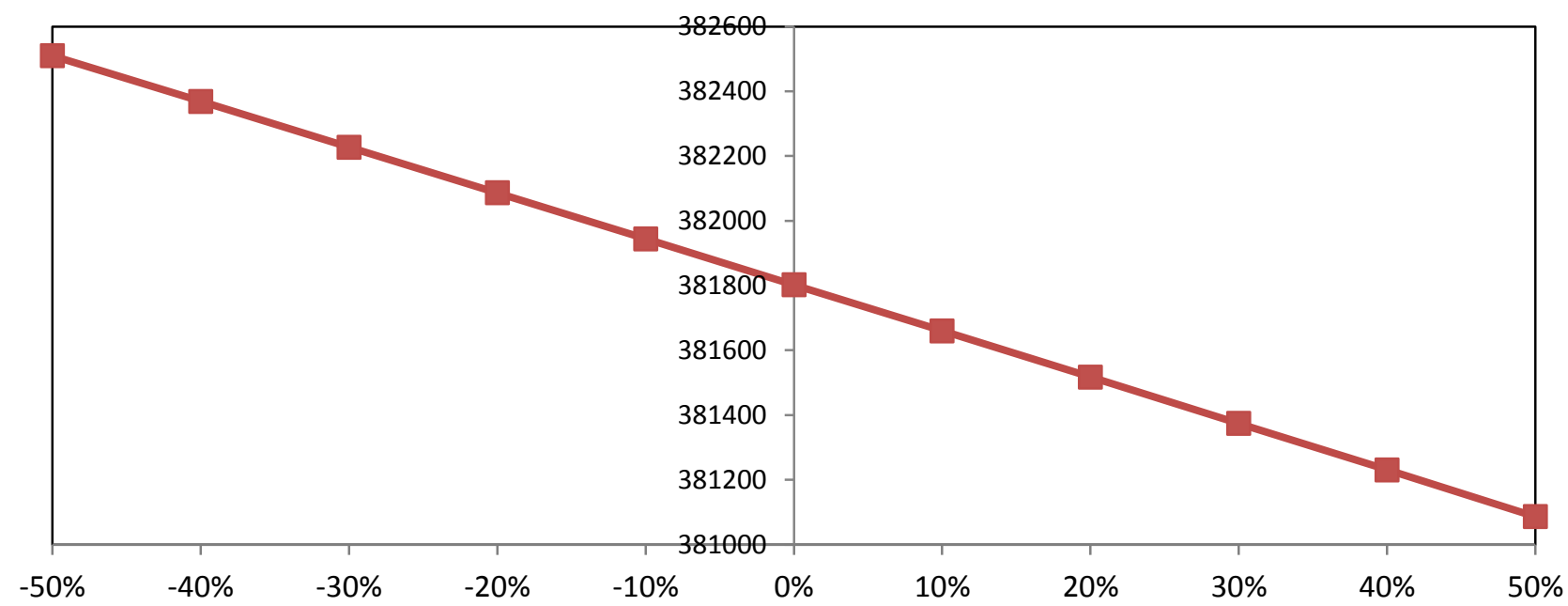

Figure 7: The impact of grey defective rate on total profit per unit time (first example)

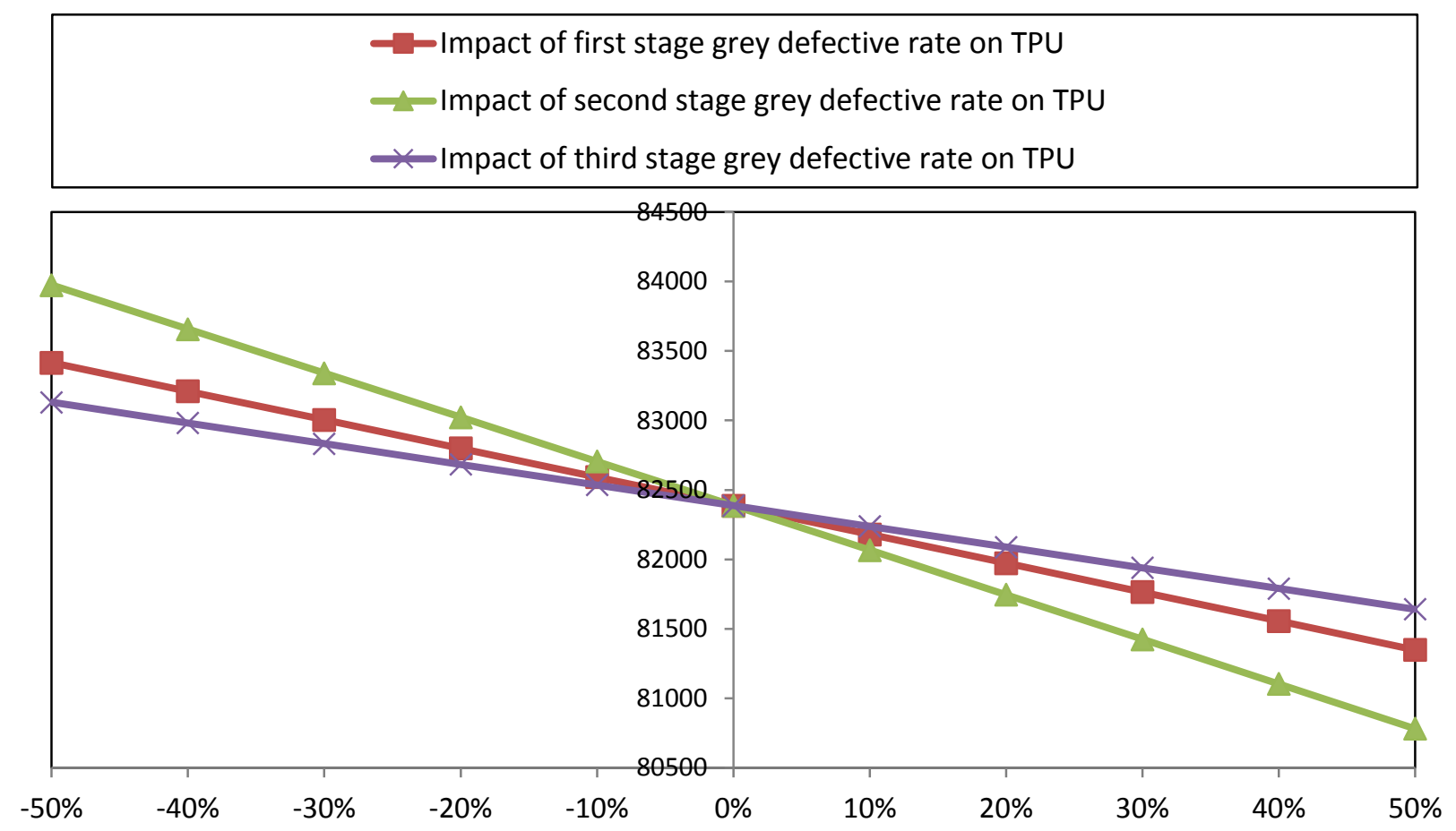

Figure 8: The impact of first, second and third stage grey defective rates on total profit per unit time 